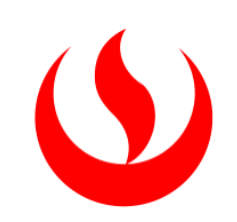

UNIVERSIDAD PERUANA DE CIENCIAS APLICADAS

FACULTAD DE PSICOLOGIA

CARRERA DE PSICOLOGIA

\title{
Representaciones de Masculinidad en un grupo de madres solteras de San Juan de Lurigancho
}

\section{TESIS}

Para optar el Titulo Profesional de : Licenciada en Psicología

\author{
AUTOR \\ Abusada García Pacheco, Alejandra Lucía (0000-0003-1365-4065)
}

ASESOR DE TESIS

Tagliabue Ganoza, Regina (0000-0002-2254-5517)

Lima, 4 de Julio 2018 


\section{RESUMEN}

La presente investigación se propuso describir como se construyen las representaciones de masculinidad en un grupo de madres soltera de San Juan de Lurigancho uno de los distritos mas grandes de Lima, Perú. El diseño fue de tipo cualitativo, desde la perspectiva de estudio de casos, lo que permitió comprender el proceso de construcción de las representaciones de masculinidad. Las técnicas para la recolección de la información fueron entrevistas a profundidad basadas en la teoría de sistemas conversacionales propuestas por Gonzales Rey (2007). A partir de las narrativas de estas mujeres, se realizó un análisis cualitativo que permitió extraer ejes centrales con sus respectivas categorías, lo cual permitió dar cuenta de los aspectos importantes en sus representaciones. Los resultados de esta investigación fueron interpretados desde un marco psicoanalítico y social, los cuales se espera que puedan ser de utilidad para orientar programas de intervención en la población.

Palabras clave: Representaciones, masculinidad, género, social, empoderamiento. 


\begin{abstract}
The aim of this research thesis is to explore the representations of masculinity within a group of single mothers from San Juan de Lurigancho, one of the biggest districts in Lima, Peru. The design is qualitative, using a case study perspective, which allowed us to understand the construction of representations of masculinity. The main technique used for data recollection was deep interview by means of conversational systems introduced by Gonzales Rey (2007). Based on the narratives shared by these women, a qualitative analysis allowed us to extract the central mainstay and its corresponding categories, which allowed to realize the important aspects in the representations. The results were interpreted using a psychoanalytic and social perspective. It is expected that this information may be useful for future intervention programs among the population.
\end{abstract}

Palabras clave: Representations, masculinity, gender, social, empoerment. 


\section{TABLA DE CONTENIDO}

CAPITULO 1. INTRODUCCION ....................................................................... 6

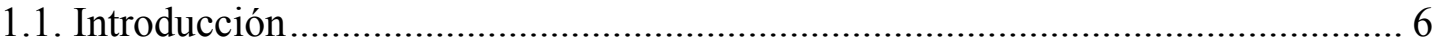

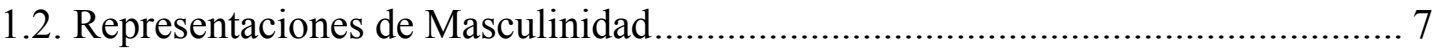

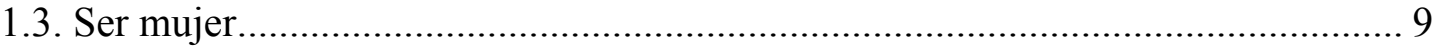

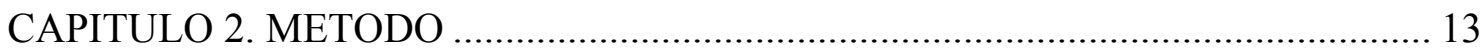

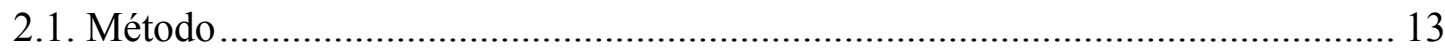

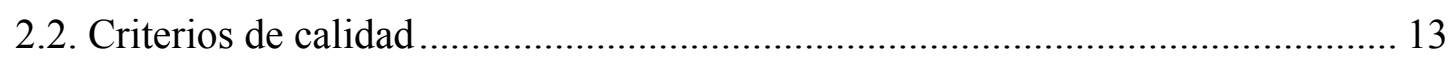

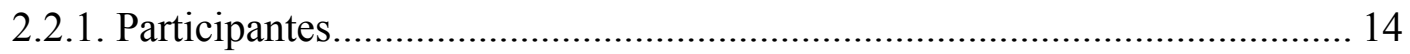

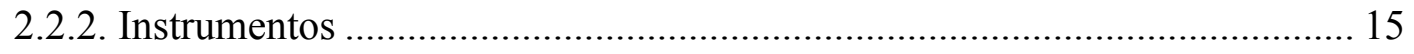

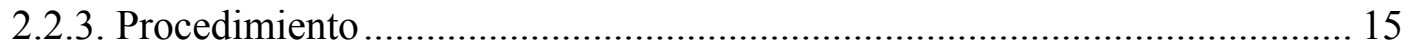

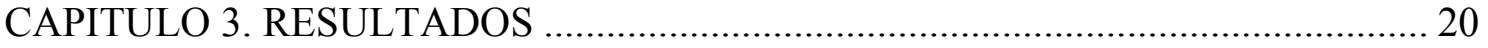

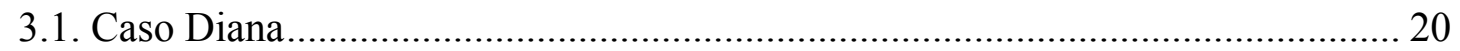

3.1.1. Ser Hombre ......................................................................................... 20

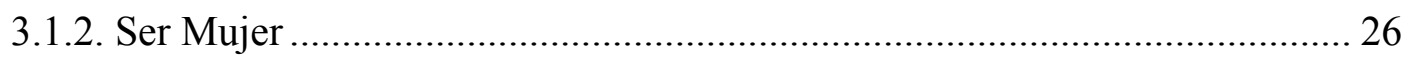

3.1.3. Vínculo con la pareja: Idealizado, infantilizado, denigrado ........................ 29

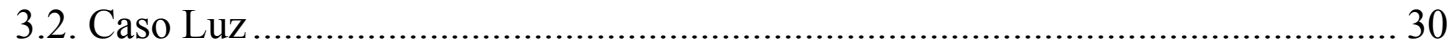

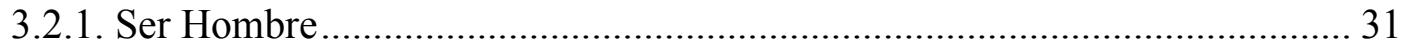

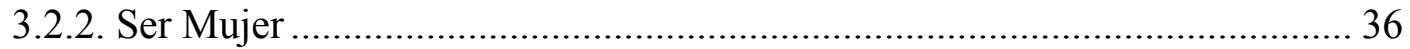

3.2.3. Vinculo con la pareja: Infantilizado, denigrado. ........................................ 40

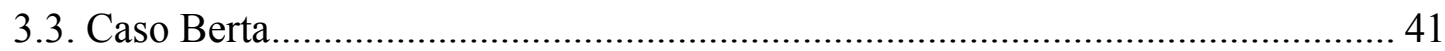

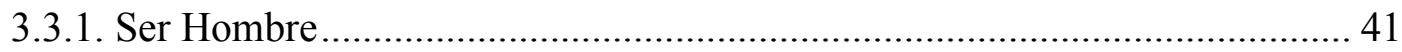

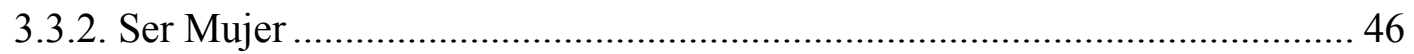

3.3.3. Vínculo con la pareja: infantilizado e idealizado ........................................ 48

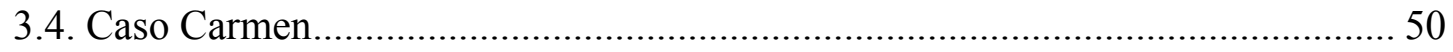

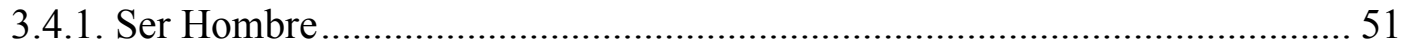

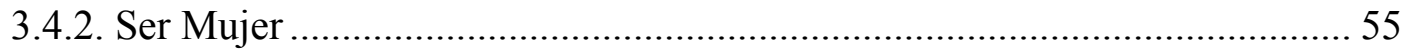

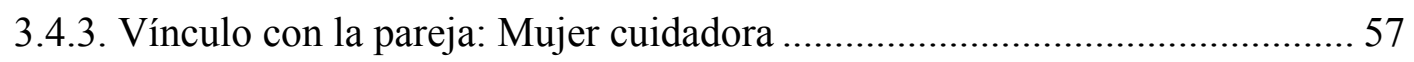

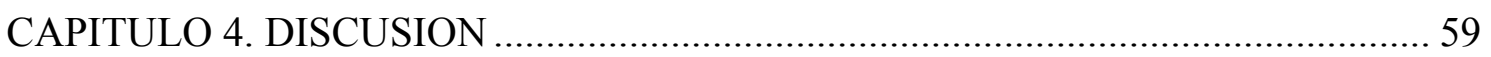

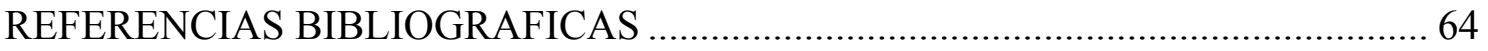




\section{INDICE DE TABLAS}

Tabla 1. Datos de las entrevistas realizadas 15

Tabla 2. Ejes temáticos encontrados en las entrevistas 


\section{CAPITULO 1. INTRODUCCION}

Representaciones de masculinidad en un grupo de madres solteras de San Juan de Lurigancho.

\subsection{Introducción}

En la actualidad en el Perú existe un desequilibrio de género, lo cual coloca a la mujer en una posición vulnerable dentro del marco social. La diferencia entre mujeres y hombres que se torna en desigualdad se explica por factores del entorno social y cultural, y no por la naturaleza. Existen condiciones que legitiman roles, espacios y características que se atribuyen a mujeres y varones de forma diferenciada $\mathrm{y}$ jerarquizada en su valoración, lo que se instaura también en las representaciones mentales de los individuos. Mientras estas condiciones sigan arraigadas en la mentalidad colectiva, las mujeres seguirán viéndose afectadas a nivel psicológico y social (MIMP, 2014).

En la última investigación del Instituto Nacional de Estadística e informática (2014), se indica que los hogares que tienen como jefa del hogar a una mujer, representaron el $26.5 \%$ del total de hogares. Los hogares monoparentales, constatan un predominio jefaturados por mujeres solas. Del total de hogares monoparentales, el 18\% fue conducido por hombres y el $82 \%$ por mujeres. Sumado a esto, de acuerdo a la distribución porcentual de las madres solteras, el distrito de San Juan de Lurigancho se clasifica como el distrito que alberga a la mayor cantidad de madres solteras $(10.4 \% \mathrm{o}$ 18,988. INEI 2014). Respecto al año 2004, la responsabilidad femenina en la conducción de los hogares se ha incrementado en 4,7 puntos porcentuales. Tomando en cuenta las estadística y los planteamientos teóricos realizados en el Perú, se considera relevante realizar una investigación acerca de las representaciones de masculinidad en este distrito representativo de la capital.

Según diversos estudios (Callirgos 1996; Connel 1997; Fuller ,2012; Guzmán \& Díaz, n.d), se plantea que la sociedad se encuentra regida por un principio de masculinidad hegemónica. Esta se define como una práctica genérica en la que se acepta 
la posición dominante de los hombres y la posición subordinada de las mujeres. Esta práctica, influye de gran manera en las dimensiones sociales, públicas y domésticas, las mujeres se ven en constante enfrentamiento con este modelo de hombre y sus expectativas en la vida como mujer, respecto a la elección de su pareja y el ideal de familia que construyen (Connel, 1997). Así mismo, respecto a la crianza de sus hijos y la posición que ellas como mujeres ocupan en el marco del hogar que construyen.

Siguiendo estas investigaciones, se encuentra también que la masculinidad hegemónica, está presente desde lo social imaginario y mediante el proceso de representación psíquica se instala en el psiquismo de la persona donde residen los sentimientos y deseos propios, que luego se convertirán en experiencias simbólicas que dará lugar a las identidades (Sanchez, 2010) Así mismo, Gutmann \& Viveros Vigoya (2005) investigaron en una población masculina latinoamerica encontraron que se refleja un doble sistema de masculinidad, en el que el hombre constantemente se ve en una disyuntiva que compromete su orden público social y el deber de ser el principal proveedor económico, lo cual en ciertas ocasiones resulta en disyuntivas especialmente con las mujeres. Otra investigación relevante fue la de Montesino (2004), que encontró en un grupo de hombre de clase media, una asignación basada en la estructura económica. Las mujeres estarían dedicadas al espacio privado que supone trabajo no remunerado y al hombre el dominio del espacio público.

Este juego de representaciones femeninas y masculinas se interiorizan y pasan a formar parte de su subjetividad y está presente en la manera en como ellas estructuran sus vínculos en distintos escenarios con figuras masculinas.

\subsection{Representaciones de Masculinidad}

Apoyándonos en la definición de Sergei Moscovici (1979) una representación es un cuerpo de organizaciones psíquicas de conocimientos aprendidos. Por medio de estas categorías, las personas se interpretan a sí mismos y al mundo externo en un intercambio constante con las realidades cotidianas. (Moscovici, 1979 en Mora, 2002)

Si bien una representación se vive subjetivamente, el proceso en el que cada uno elabora su representación de la realidad se ve influenciado por las representaciones colectivas culturales y temporales. Por otro lado, Benjamín (1997) construye las ideas de representación vinculada a las relaciones objetales basadas en la internalización 
psíquica y la representación de las interacciones del si-mismo y los objetos. Estas representaciones van siendo incorporadas por las persona en base a la vivencia de sus relaciones vinculares y las construcciones sociales y pasan a formar parte de la propia subjetividad. Los individuos, creamos nuevas significaciones de acuerdo con historias personales y unidas, prácticas intrapsiquicas las cuales se extienden más allá de las categorías culturales lingüísticas. (Benjamin, 2007; Chodorow, 1999)

El ámbito social se encuentra presente en todas las situaciones a través de los sujetos que intervienen dentro de un contexto social especifico en que se sitúan los individuos y el dialogo que se da entre ellos (Jodelet, 2008). Como señala Moscovici (1979) las representaciones sociales se dan a través de un núcleo figurativo, en el cual el núcleo central asume la organización de los elementos del campo representacional, mientras que en la periferia se encarga de adaptar las representaciones al contexto particular. Mientras el núcleo es normativo, lo periférico es funcional para la persona. Lo nuclear se encuentra relacionado a la historia colectiva, valores, normas, ideologías centrándose en lo colectivo para ver el mundo y ser parte activa de este. La periferia, actualiza las normas del núcleo en contextos particulares. (Moscovici,1981, como se citó en Dos Santos, 2009)

Tomando en cuenta las representaciones de género, cada cultura de manera individual establece las prácticas, ideas, discursos y representaciones que se atribuyen en particular a mujeres y hombres. (Fuller, 1999) Esta construcción simbólica, denominada género, reglamenta y condiciona la conducta objetiva-subjetiva de las personas. Mediante el proceso de constitución del genero, crea ideas sobre lo que es representativo del hombre y de la mujer, de lo que se supone es propio de cada sexo. (Lamas, 1996). Lo considerado masculino es el poder y la participación en la esfera pública, y lo femenino se representa con la ternura y crianza de los hijos en la esfera privada (Callirgos, 1996).

Con respecto a las representaciones de lo masculino, diversos estudios caracterizan a la subjetividad masculina como opuesta a la identificación con lo femenino (representado en la madre), lo infantil y lo homosexual, para lograr su posicionamiento de dominio y control, de esta manera alcanzar el ideal de autosuficiencia hasta culminar en la paternidad. Este hecho se considera como la cúspide de la masculinidad exteriorizada, al tener hijos y mantener una familia. (Montesinos, 2004) Las representaciones de masculinidad no solo son las diversas expresiones individuales de lo masculino, se basan en una serie de normas, mandatos 
que legalizan apego al modelo masculino. Estos elementos forman parte de un núcleo resistente de las representaciones que difícilmente se modifican. La masculinidad se define en tres mandatos que ayudan a explicar las representaciones; sexualidad controladora, ser proveedor, y distanciamiento de la esfera domestica. (Fuller, 1997)

Fuller (1996) en su estudio de la sociedad peruana, plantea la polaridad representada como el marianismo y el machismo. Esto gira entorno a la imagen de pureza sexual que sostiene la dignidad de la mujer, y como es que desde el espacio privado, tiene un poder del hombre y del espacio público. Con relación al otro polo, el machismo, la sociedad le otorga el deber de sexualidad activa y exteriorizada al hombre, probando de esta manera su masculinidad. A nivel social, esto supone una jerarquía en la cual no necesariamente el hombre tiene que tener poder sobre la mujer, sino la diferencia se encuentra en el lugar donde se ejerce este poder. En el caso de los hombres, tienden a ejercerlo en el espacio público y las mujeres en el privado. Estas jerarquías dicotómicas se contraponen para crear un equilibrio entre lo que se cree que es de la mujer y del hombre (Fuller, 1996)

Sin embargo, estos rasgos tradicionales en la actualidad son cuestionados por el surgimiento de un nuevo ideal masculino: ser sensible y empático, el cual conflictua al varón con los tradicionales criterios de su masculinidad (Burin, 2004). Callirgos (1996), plantea que a pesar de algunos intentos por despolarizar la sociedad, mucho cambia en apariencia pero no en el fondo donde aparecen los preceptos más tradicionales, y he aquí donde entra la formacion de las representaciones sociales de la masculinidad.

\subsection{Ser mujer}

La construcción de la identidad femenina, es también el producto de el condicionamiento social y jerárquico. Desde temprano, se va construyendo desde los modelos sociales que se incorporan la pisque desde una época muy temprana de la vida. (Person, 2007). A partir esta perspectiva se va considerando desde la propia subjetividad una posición jerárquica superior para los hombres que se plasman como dueños de mayor conocimiento, status superior y proveedores de seguridad. Asimismo, Tyson (2000) plantea que a lo largo del proceso de desarrollo se van dando identificaciones con elementos del mismo sexo o del sexo opuesto, lo que influye en la identidad personal. La identidad personal se suma con el sexo biológico y esto 
determina la manera en que un individuo construye su propia definición de su masculinidad o femineidad. Si bien la cultura tiene influencia en esta identidad, es cada individuo de manera personal, basándose en experiencias previas y su propio complejo sistema de creencias, que va a tener un sentido de si mismo ya sea masculino o femenino (Tyson, 2000)

La identificación personal, se relaciona con los roles de género, basados en un patrón de interacciones conscientes o inconscientes que una persona sostiene guiados por el género, es decir una persona también se identifica a si misma debido a lo que cree conveniente llevar a cabo bajo la normativa que la sociedad impone para delimitar la barrera entre lo masculino y femenino (Gutmann, 2005). Si bien estos roles se adquieren también mediante la cultura y sociedad, la identificación refiere a una representación intrapsíquica que interactúa de manera dinámica con el entorno (Tyson, 2000) Este tipo de interacciones se construyen en el self desde el nacimiento y durante toda la etapa del desarrollo consolidándose en las representaciones de las interacciones, relaciones y diálogos con los objetos. Estas representaciones de las relaciones constituidas por los roles se entrelazan con aspectos de consciencia de género, de tal manera que la identidad individual se ve influida por los roles masculinos y femeninos (Sandler \& Sandler, 1978).

Lo femenino no puede existir si no es en contraposición con lo masculino y viceversa. Lo femenino se encuentra relacionado estrechamente con el sentimiento, la interacción con otros (Chodorow, 1999; Fuller, 2000) En el mundo occidental, la reproducción y crianza de los hijos es el núcleo de la diferenciación entre hombres y mujeres, la maternidad se atribuye como una de las características más estables a nivel psicológico. La sexualidad, maternidad y emociones están asociadas a su identidad de ser mujer (Fuller, 1998).

La masculinidad es concebida como esta es una suerte de construcción, que debe ser lograda compitiendo con otros hombres para luego posicionarse en un rol de jefe de familia, que provee y protege a los suyos. El estatus masculino debe ser merecido, ya que debe enfrentarse al cuestionamiento de otros varones y a alcanzar la valla que se plantea la cultura acerca de lo que implica ser masculino. (Connel, 1997) Los aspectos naturales de la masculinidad se centran en la fuerza física y los órganos sexuales, estos son considerados como el núcleo de lo masculino fundados en características innatas del mismo género. Sin embargo en representación de lo masculino deben convertirse en sexualidad activa, vigor y valentía (Fuller, 1999). 
Aunque la opinión femenina, sobre los roles apropiados para cada genero se viene ampliando y transformando con los años, los propios prejuicios todavía se evidencian en los pre conceptos de hombres y mujeres. Actualmente, la mujer ha ido teniendo mas relevancia en los espacio públicos (Montesinos, 2004). Esta nueva identidad representa el inicio de un proceso en que el poder masculino se ve tambaleante. Esto supone las perdidas de control sobre las principales fuentes de poder como la del rol proveedor, fortaleza y racionalidad. Las mujeres van cumpliendo con nuevos roles sociales, nuevas formas de pensar y por lo tanto nuevas formas de relacionarse con su propia identidad de género. (Montesinos, 2004) Este cambio implica muchos aspectos, las mujeres ya no se auto valoran únicamente como objetos del deseo sexual ajeno, se encuentran mas dispuestas a velar por su propia satisfacción.

Las mujeres están en medio de un proceso de cambio merced al cual ya no se auto valoran principalmente como objetos del deseo sexual ajeno, sino que están más dispuestas a expresarse como sujetos deseantes. Este proceso demuestra cómo se han venido modificando las propias teorías de sexo y genero y las vinculaciones con cuestiones ligadas al poder y jerarquía. (Person, 2007)

En la construcción de la identidad, en las mujeres más tradicionales predomina en ellas la identificación con sus propias madres en cuanto al ideal maternal. En paralelo las mujeres categorizadas como "innovadoras" no se identifican con el clásico ideal maternal de sus propias madres sino que más bien en la construcción de su identidad incorporan aspectos identificatorios con ideales de la función paterna tradicionalmente masculinos, como por ejemplo habilidades y destrezas para conseguir recursos económicos y priorizando estas competencias sobre la posibilidad de un ejercicio materno tradicional como única alternativa de identidad. (Burin, 2007) La idea es que la mujer "liberada" no necesita amoldar su imágenes a los modelos masculinos de poder sino que pueda crear su propio modelo (Person, 2007).

Como se ha mencionado, las representaciones de masculinidad son un complejo fenómeno que se encuentra en constante metamorfosis. Desde los datos estadísticos y las investigaciones realizadas sobre el tema en cuestión se pueden abrir puertas a nuevas investigaciones.

Comúnmente se han realizado estudios a nivel social y con población masculina pero poco se ha investigado sobre las representaciones de masculinidad como parte de la identidad femenina, lo que hace relevante la presente investigación. Por lo tanto cabe 
preguntarse ¿cómo han ido construyendo estas mujeres sus representaciones de masculinidad a lo largo de su experiencia de vida?

En esta línea, la presente investigación se plantea como objetivo describir como se construyen las representaciones de masculinidad en un grupo de madres solteras en San Juan de Lurigancho. 


\section{CAPITULO 2. METODO}

\subsection{Método}

La presente investigación se realizó bajo un método cualitativo de estudios de casos, basado en la construcción de conceptos mediante la subjetividad individual, la cual será accesible a través del estudio de la singularidad (Stake, 1995; Gonzales Rey, 2006). Para llegar a las construcciones subjetivas, se aplicaron los métodos conversacionales propuestos por Gonzales Rey (2006). La dinámica conversacional, tiene como objetivo conducir a la persona estudiada a campos significativos de su experiencia personal, capaces de implicarla en el sentido subjetivo de los diferentes espacios que configuran su subjetividad. Va expresando en el espacio de estos relatos, su mundo, necesidades, conflictos y reflexiones, lo que implica ir captando indicadores y elementos de esta que nos permita la continuidad de la expresión de la otra persona en temas de interés para él (Gonzales Rey, 2006).

\subsection{Criterios de calidad}

La presente investigación cumple con los cuatro criterios de calidad planteados por Calderón (2009). Estos fueron adecuación epistemológica, reflexividad, relevancia y validez. (Calderón, 2009).

En cuanto a la adecuación epistemológica, la investigación fue abordad desde una metodología cualitativa. Se aplico un diseño metodológico que permitió abordar el objetivo de la investigación, generando ejes de análisis para poder comprender el fenómeno estudiado desde la subjetividad de las participantes.

Con respecto a la relevancia esta investigación ha generado hallazgos que apoyan una realidad actual y muestran una urgencia por la salud mental de la mujer peruana. Esta investigación es útil para generar nuevos modelos de intervención que se deben trabajar e interiorizar en centros de atención primaria de salud mental. La metodología da cuenta de la importancia de generar espacios de auto observación y escucha para interiorizar las propias vivencias. 
Con respecto a la validez, existió rigurosidad en el recojo de información y transcripción de la misma, teniendo suma minuciosidad al recoger los relatos y narrativas de las participantes. El instrumento fue validado por cuatro expertos en el tema, los cuales aprobaron la eficacio del mismo para recoger la informacion que ayude a contestar la respuesta de investigacion y cumplir con el objetivo. Con respecto al analisis de la información, la investigadora tuvo constantes asesorias con un experto lo cual permitio una profundidad en el analisis y rigurosidad en los resultados.

Finalmente la reflexividad ha sido fundamental en la investigación. Se utilizó el método de Gonzales Rey (2007) que pone la subjetividad de la propia investigadora al servicio de la investigación. Se hicieron varios análisis de este fenómeno con la asesora experta.

\subsubsection{Participantes}

Las informantes son 4 mujeres adultas de 22 a 38 años de edad, que decidieron participar voluntariamente en el presente estudio (Tabla 1). Se trata de un grupo de mujeres que viven en un asentamiento humano en el distrito de San Juan de Lurigancho. En cuanto al distrito de residencia, es el mas grande de Lima con 1 millón 700mil habitantes, (INEI, 2015). El asentamiento funciona como una comunidad en la que los vecinos mantienen entre ellos una relación de apoyo y soporte. Las mujeres entrevistadas pertenecen al nivel socioeconómico D.

Son madres solteras, tienen una pareja con quien mantuvieron una relación esporádica; en un inicio hubo una relación estable con la pareja en cuya época tuvieron los hijos. Luego de tener los hijos, la relación se volvió inestable no viven en casa pero tienen contacto esporádicamente. Ellas asumieron la jefatura del hogar y son el soporte económico, sin embargo siguen incluyendo al padre de sus hijos en la dinámica familiar. Para el caso del presente estudio las mujeres participaron voluntariamente y manifestaron el interés por compartir sus historias con la investigadora y fueron seleccionadas con un muestreo homogéneo.

Con respecto al número de participantes, se tomó el criterio por saturación teórica. Con respecto al muestreo, este fue no probabilístico. 
Tabla 1. Datos de las entrevistas realizadas

\begin{tabular}{lccccc}
\hline $\begin{array}{l}\text { Nombre } \\
\text { ficticio }\end{array}$ & Edad & Procedencia & $\begin{array}{c}\text { Número y } \\
\text { sexo de los } \\
\text { hijos }\end{array}$ & $\begin{array}{c}\text { Número de } \\
\text { entrevistas } \\
\text { realizadas }\end{array}$ & $\begin{array}{c}\text { Situación } \\
\text { Laboral }\end{array}$ \\
\hline $\begin{array}{l}\text { Berta } \\
\text { Diana }\end{array}$ & 36 & Cajamarca & $1(\mathrm{~F})$ & 2 & $\begin{array}{c}\text { Empleada } \\
\text { doméstica } \\
\text { Luz }\end{array}$ \\
38 & Piura & $4(\mathrm{M}, \mathrm{M}, \mathrm{F}, \mathrm{F})$ & 2 & 2 & $\begin{array}{c}\text { Construcción } \\
\text { Costurera }\end{array}$ \\
Carmen & 30 & Chiclayo & $3(\mathrm{~F}, \mathrm{M}, \mathrm{F})$ & 2 & Costura \\
\hline
\end{tabular}

Fuente: Elaboración propia

\subsubsection{Instrumentos}

En un principio se hizo uso de una ficha sociodemográfica (ANEXO A) que busca conocer los aspectos relevantes de las informantes para esta investigación (Edad, grado de instrucción, número de hijos, ocupación).

Luego, se hace uso de una guía conversacional validada por expertos. Para la primera sesión, se incluyó una pregunta generadora Háblame de tus amores (ANEXO B), que buscó evocar las relaciones más significativas con las figuras masculinas importantes en su vida.

En la segunda sesión, la pregunta eje fue «Háblame de los amores de tu infancia» (ANEXO C) la cual se inclinó a evocar una construcción de la historia familiar haciendo un recorrido de sus vínculos y relaciones con figuras representativas. Ambas sesiones se realizan en igualdad de condiciones, contando con la debida privacidad para cuidar la confidencialidad de la informante e inducir a la veracidad de los relatos.

Por otro lado, se utiliza la observación no estructurada durante las entrevistas para recoger aquella información resaltante sobre su estado afectivo que se manifieste en la conducta física de la informante.

\subsubsection{Procedimiento}

La investigadora tenía contacto con una de las mujeres de la zona a partir de una actividad de beneficio comunitario. Luego de un tiempo, la investigadora se comunicó con una de las mujeres líderes de la zona y a través de ella se tomó se contacto con las informantes que reunían las características mencionadas para la investigación. Se hizo 
un primer contacto de familiarización, en un espacio que facilitó la representante vecinal. En un principio, se realizó un piloto que consto en una entrevista a una de las informantes voluntarias. El piloto permitió realizar ajustes en el método de recolección de datos: Incorporar las preguntas ejes y centrar los temas para cada sesión. Se logró tomar conciencia de la importancia de una pregunta generadora, la cual se incorporó posteriormente.

Con respecto a la recolección de datos, se realizó mediante entrevistas a profundidad usando las guías de entrevistas anteriormente verificadas por 4 expertos, especializados en psicología clínica y con investigaciones en el área social.

Las conversaciones fueron grabadas con la autorización de estas mediante un consentimiento informado (ver ANEXO D). La aplicación individual se llevó a cabo mediante dos entrevistas en semanas consecutivas los días Domingo. Las conversaciones indagaron la historia familiar, relaciones con figuras parentales, fraternales, y de parejas y fueron transcritas textualmente, cambiando algunos nombres para cuidar la confidencialidad de las informantes. En la tercera entrevista, se alcanzó el punto de saturación, sin embargo se realizó un caso más para mayor enriquecimiento del estudio. En el proceso de investigación, si hubiera necesidad de una ayuda psicológica especializada, se tomó contacto con una institución privada y una ONG para que pudieran ser lugares donde las participantes pudieran recurrir.

En cuanto al procesamiento de la información, luego de realizadas las dos conversaciones a profundidad con cada participante, se analizaron y se fueron construyendo las zonas de sentidos que propone Gonzales-Rey (2007) y de esta se identificó los ejes y sus categorías.

Se construyeron dos ejes principales; Ser hombre y Ser mujer. Para el análisis de cada eje, se elaboraron algunas categorías con la finalidad de organizar la información. Para la triangulación también se tomó en cuenta los datos recogidos de la observación no estructurada que se realizó durante las entrevistas. Siguiendo este procedimiento de análisis de la información, se llegó al objetivo de describir cómo se han construido las representaciones de masculinidad en este grupo de mujeres. Los casos fueron analizados desde su singularidad (Stake, 2005) clasificando la información encontrada en el discurso en los ejes mencionados, contrastando con la observación y teoría.

Luego del análisis de la información con los principales ejes, se construyó un tercer eje Vínculo con la pareja, el cual destacó por la presencia de este aspecto en la vida de las informantes. 
Tabla 2. Ejes temáticos encontrados en las entrevistas

\begin{tabular}{c|c|c}
\hline Ser hombre & Ser mujer & Vínculo con la pareja \\
\hline Proveedor & En el trabajo & Idealizado \\
Infiel & En la casa & Denigrado \\
Pseudo presente & & Infantilizado \\
\hline
\end{tabular}

Fuente: Elaboración propia

A continuación se explicarán los ejes temáticos planteados en la tabla anterior.

\section{EJE: SER HOMBRE}

A través de este eje, se expresan las representaciones de masculinidad en la manera que las mujeres representan lo masculino y entienden lo que es ser hombre con respecto también a su identidad. Esta representación va ir cambiando mediante las experiencias y reflejándose en sus relaciones con hombre y mujeres, integrara también la manera en que pueden verse a sí mismas y adoptar aspectos masculinos en la construcción de la propia identidad.

Las representaciones se entienden como un cuerpo de organizaciones psíquicas de conocimientos aprendidos. Por medio de estas categorías, las personas se interpretan a sí mismos y al mundo externo en un intercambio constante con las realidades cotidianas. (Moscovici, 1979 como se citó en Mora, 2002) Tomando la investigación de Fuller (1997) en países latinoamericanos, los tres mandatos básicos que ayudan a entender las representaciones de masculinidad; sexualidad controladora, ser proveedor, y distanciamiento de la esfera doméstica.

\section{Categoría: Proveedor}

Mediante esta categoría, se puede explicar la creencia sostenida de que el hombre debe ser el principal proveedor económico del hogar, lo cual se acompaña de su compañía, seguridad, una suerte de pilar para la mujer. Con respecto a la categoría, se refiere que el hombre constantemente se ve en una disyuntiva que compromete su orden público social y el deber de ser el principal proveedor económico, lo cual en ciertas ocasiones resulta en disyuntivas especialmente con las mujeres. (Montesinos, 2004).

\section{Categoría: Infiel}

La categoría "infiel" responde a la creencia que el hombre, tiene que probar su poder fuera del espacio privado. Es común que las mujeres esperen que el hombre les 
vaya ser infiel o vaya a tener muchas mujeres, es parte de la representación masculina que tienen arraigada. Apoyándonos en el estudio de Fuller (1996), la sociedad le otorga al hombre, el deber de sexualidad activa y exteriorizada, probando de esta manera su masculinidad.

\section{Categoría: Pseudo presente}

Esta categoría responde a la manera en que las mujeres mantienen presente al padre de sus hijos en la vida cotidiana y en la crianza de estos aún cuando no cumple un rol fundamental en sus vidas. Esta categoría explica la manera en que la madre niega la ausencia y mantiene presente a la pareja en su vida y en la de sus hijos. Se ve al hombre con una cualidad intermitente, involucrando en una relación inestable en la cual la prima ambivalencia afectiva.

\section{EJE: SER MUJER}

El eje "ser mujer" engloba la construcción de la propia identidad, es también el producto del condicionamiento social y jerárquico. Desde temprano, se va construyendo desde los modelos sociales que se incorporan a la pisque desde una época muy temprana de la vida. La identidad personal se suma con el sexo biológico y esto determina la manera en que un individuo construye su propia definición de "ser mujer". Si bien la cultura tiene influencia en esta identidad, es cada individuo de manera personal, basándose en experiencias previas y su propio complejo sistema de creencias, que va a tener un sentido de sí mismo ya sea masculino o femenino (Tyson, 2000).

\section{Categoría: En el espacio privado}

Esta categoría explica como las mujeres se ven a si mismas desde su hogar, y lo que implica este espacio dentro de su propia identidad.

Tomando la definición de Fuller (1997) surge el concepto de marianismo que prima en las sociedades occidentales. Esto refiere al poder que ejerce la mujer desde el espacio privado, lo cual forma parte de la identidad de ser mujer.

\section{Categoría: En el espacio público}

Las mujeres han comenzado a tener poder en este, ya sea consiguiendo trabajo o convirtiéndose en proveedoras de familia. En los últimos años las mujeres vienen tomando dominio del espacio público (Montesinos, 2004). Estos cambios también 
realizan modificaciones en su propia identidad, en la cual ya no se ven pasivas ante el trabajo o espacio social, ahora participan de manera activa en estos. La participación en el espacio publico influye en la manera que las mujeres construyen lo que entienden por “ser mujer" y a la vez sus representaciones de masculinidad.

\section{EJE: VINCULO CON LA PAREJA}

Este eje surge del relato de las participantes y es construido por las representaciones tanto de lo masculino como lo femenino.

Mediante el análisis cualitativo de las entrevistas, se observa que emerge una pauta vincular en cada caso, la cual marca la relación que las mujeres tienen con sus figuras masculinas representativas. Se encuentra un proceso común que transcurre por estos tres mecanismos: Idealización, denigración e infantilización.

En un principio, lo idealizan creyendo que les dará una familia, protección y compañía. Se idealiza también la idea de familia y al hombre como proveedor de hijo. Luego se da un punto de quiebre en el cual descubren una infidelidad y de la idealización pasan a denigrarlos tomando distancia de las parejas y en el a posteriori retoman el vinculo infantilizándolos. 


\section{CAPITULO 3. RESULTADOS}

\subsection{Caso Diana}

Diana es una mujer de 38 años, físicamente, es una mujer de contextura gruesa. Usa maquillaje, cabello recogido con una cola y viste ropa ceñida. Tiene cuatro hijos con la misma pareja, dos mujeres, dos hombres en edad adolescentes. Actualmente se encuentra separada del padre de sus hijos debido a una infidelidad.

Diana nació en Trujillo, fue criada por sus padres. Estudio secundaria incompleta y a los 18 años se mudó a lima para trabajar y buscar más oportunidades laborales, actualmente trabaja en una compañía de construcción como supervisora de obra.

Cuenta que desde pequeña, su familia le inculcaba la idea que las mujeres estaban destinadas a sufrir por las parejas que eligieran. Comenta que en el núcleo familiar se enfatizaba la idea que ellas solo pertenecían a la casa, para cuidar a sus hijos y ser el pilar de la familia. Diana manifiesta que se ha visto obligada a tomar las riendas de su hogar y ser ella quien salga a trabajar y mantenga a sus hijos.

Se muestra dispuesta a colaborar con las entrevistas, sin embargo en los primeros minutos se percibe cierta resistencia a hablar de temas que la conecten con sentimientos. Conforme transcurren las entrevistas y se tocan distintos temas, su narrativa se torna más fluida, lo que hace más fácil la conversación.

\subsubsection{Ser Hombre}

\section{Ser proveedor: acompaña, cuida y da lo que necesitas}

"Te vas a quedar sola, no te quedes sola... tienes que buscar a alguien que te acompañe, que te cuide, un hombre, mamita que te de lo que necesitas". (Diana, entrevista)

Diana refiere que desde pequeña, su padre le inculcaba la creencia de que tenía que encontrar un hombre que le sirva como proveedor económico, de compañía y cuidado. 
Así mismo, su madre le dejaba en claro que las mujeres estaban hechas para el hogar, cuenta que siempre le repetía lo siguiente

"Que nosotras seamos solo para la casa, para casarnos, que nos den así. Que el estudio no se ha hecho casi para las mujeres. Así me decía. Más seguro que estudien para mamá y para esposa”. (Diana, entrevista)

Sus hermanos y tíos también reforzaban la misma idea, no la dejaban decidir e insistían para que se quedara aceptara al padre de sus hijos, para que no "se le pase el tren”. Se puede apreciar en la siguiente viñeta

“En sí, mis tíos, los hermanos de mi papá, mis hermanos le querían bastante a él, todos querían que sea de la familia. Me hablaban de un lado, me hablaban del otro lado...me convencieron...todo era el, por un lado y por el otro, ya no me dejaban que siquiera converse con otros" (Diana, entrevista)

Si bien en un principio estos no eran sus propias creencias, la figura masculina más importante que tenía (su padre) le reforzaba esta manera vincularse con lo masculino. Describe estas ideas desde las voces de otros, de las que se apropia sin tomar conciencia.

En su adolescencia, cuando recuerda como conoció al que sería el padre de sus hijos. Diana no se explica cómo formo una familia con él, menciona que no se sentía segura de sus sentimientos.

Piensa que se dejó llevar por la promesa de contar con un hombre que la provea en todo sentido. Esto además materializa el discurso que había recibido durante su infancia. Pareciera que se deja seducir por las palabras que le dice el enamorado, ya que son lo que ella ha escuchado que "debería de ser".

"Ni yo sé... como he estado con él... será que él me decía, me hablaba pues... quiero que seas mi enamorada, que estoy enamorado de ti, te voy a dar una familia, darle todo a ti y a mis hijos, un montón de cosas”. (Diana, entrevista)

Diana lo acepta como pareja y padre de sus hijos, conviven por once años hasta que ella descubre que él le era infiel.

Cuando Diana se separa no exige que la mantenga a ella pero cuida que cumpla con sus hijas como padre proveedor. Pareciera que para Diana es legítimo defender la figura de un padre proveedor y al mismo tiempo rechaza su propia dependencia respecto 
a una pareja proveedora. A través de la figura del padre proveedor, pareciera que trata de asegurar para sus hijas alguien que les provea confianza. Esto se hace evidente en la siguiente viñeta:

"Así cualquier cosa que le pasé a ella [su hija] y yo no esté, va a confiar con su papá. Yo sé que su papá por ella... sí hace. A veces cuando ella está mal, al toque viene. Pasa cualquier problema y al toque viene. Yo lo llamo así una de la mañana, dos de la mañana, tres de la mañana, él contesta normal." (Diana, entrevista)

sfsmail@pobox.upenn.edu

Frente a la separación, el padre de Diana, también se ofrece a apoyarla con sus hijos:

"Las cosas pasan así y así, pero no es para que te quedes callada. Para eso nos tienes, a mí me gustaría que vengas a vivir con nosotros yo te voy a ayudar a dar estudio a tus hijos". (Diana, entrevista)

Aquí observamos como, la representación de lo masculino está conectado a la figura de un padre proveedor, pero se ha liberado de la figura de una pareja proveedora para ella. No quiere a alguien que la ayude a ella, pero si desea que sus tengan un padre que les provea seguridad.

Diana no solo rechaza a la pareja proveedora, sino también al padre proveedor, al no aceptar la oferta de ayuda que le hace su padre.

En este momento de su vida, Diana ya ha venido modificando sus representaciones de masculinidad, planteándose el reto que ella como mujer pueda convertirse en proveedora para ella y sus hijos. Es en este momento cuando re significa el "ser proveedor" y transforma una percepción que la tenía arraigada desde niña, incorporando ahora esta nueva representación de proveedora en su identidad como mujer. Surge en Diana, el sentir que ella tiene que enfrentar su nueva situación con sus hijos, surge en ella una fuerza de su yo que la traduce en "mi orgullo". Este orgullo representa esta fuerza que la fue empujando a enfrentar y validarse como madre proveedora.

“Jamás, dije. No. Mi orgullo es así. Jamás, asi yo no tenga, darle molestia a mi papá, a mi mamá, a mis hermanos... no. Tú, lo tuyo, yo lo mío. Gracias por preocuparte, o me llamas si estoy mal o con esto. Pero yo molestarte, o darte a uno de mis hijos para que lo tengas, para que tú le des estudio, no Solita he 
enfrentado mi problema. Solita, solita, solita, sin ayuda de nadie. Ni siquiera me he ido al psicólogo (risas). Verdad, ni siquiera al psicólogo. Te digo, estaba en el trabajo, me metí a trabajar en una fábrica..." (Diana, entrevista)

\section{Infiel: Alguien que hace sufrir}

Diana refiere tener la creencia de que su pareja por ser hombre, tenía derecho de tener sexo así ella no lo deseara. Cuenta que al principio de su relación, lo concibe como una buena persona por respetar el hecho de no querer sexo, como si esto fuera una obligación para ella y una cualidad exclusiva del hombre. Diana lo manifiesta con el siguiente comentario:

“Me respetó. Un año hemos estado saliendo, andando así...nunca me faltó el respeto. En sentido de que yo para estar con él, nunca me ha exigido... Yo veía a una buena persona. Si yo lo permitía, él lo hacía, sino no." (Diana, entrevista)

Cuando se separa de su pareja, manifiesta como para ella el hombre siempre puede tener muchas parejas y no una sola mujer.

Diana reflexiona que le gustaría ser hombre para tener muchas parejas y hacer sufrir a su ex pareja, abandonarlo como lo hicieron con ella. Claramente lo manifiesta en la siguiente viñeta:

“Cómo me hubiera gustado ser hombre y tú hubieras sido mujer, así me hubiera vengado contigo, así te hubiera hecho, te hubiera hecho así dejarte 2 - 3 hijos y ya fugarme con otra”, así le decía, y me decía: "pero ¿por qué hablas eso?, porque le digo: "no, a mí sí me hubiera gustado, yo quería a ver si me iba con otra”. (Diana, entrevista)

Seguidamente también le trasmite esta idea a su hijo, como sí el hombre estuviese predestinado a tener otras mujeres.

"Tú eres hombre, yo le digo, tú eres hombre. Tú no crees que un día puedes tu pasar por esto (refiriéndose a lo que paso con el padre de sus hijos). Un día tal vez, tienes tú señora, y te llegas a enamorar de otra persona. Haces tus locuras. ¿Yo estaría feliz de que a ti te denuncien o te metan a la cárcel? Así le digo. Eso es malo." (Diana, entrevista) 
Parece curioso, la similitud con el discurso de su padre que le anticipaba un sufrimiento por culpa de la pareja que eligiera.

"Porque mis hijas mujeres van a sufrir, mis hijos hombres no, ellos van a hacer sufrir...Mis hijas van a sufrir, porque ¿qué hombre les tocará...?” (Diana, entrevista)

Diana comenta que siente que para los hombres todo es más fácil, no tienen que enfrentarse a los sentimientos, a ser vulnerables o dañados, resalta en su discurso la cualidad de no sufrir, también destaca que una de las cosas más importantes para ellos es el sexo:

"Porque tal vez un hombre no siente... a mis hermanos les digo yo pienso que los hombres no sienten, todo es felicidad, sexo también... todo es normal lo que pasa"” (Diana, entrevista)

En el relato de Diana, pareciera que se hace una distinción en el significado de "sentir" para el hombre y para la mujer. Quizás interpreta que el "sentir" para una mujer es equivalente a sufrir, y para el hombre es gozar.

\section{Pseudopresente: negar la ausencia}

“Desilusión... claro, yo pienso no le hice daño, ni me porté mal con él, siempre le traté bien. Todo tuvo. Él no pensó en su familia y se fue con otro compromiso. Se fue. No, él no quería irse, no quería irse; sino que la chica, la señora, estaba embarazada de gemelas" (Diana, entrevista)

Frente al fuerte dolor que le causó el padre de sus hijos, Diana parece negar en su discurso que el hombre puede haberla dejado por voluntad propia, otorgándole la decisión por la presión de una persona externa.

Ante la ausencia de su pareja, Diana refiere que comienza a tener a su pareja presente en su recuerdo de una manera constante. Debido al abandono e infidelidad del hombre, cuenta que sufre una fuerte herida. Esto parece expresarse en negar la ausencia de este que a la vez influencia en el mensaje que les trasmite a sus hijos sobre su padre.

Diana parece manejarse con dobles mensajes porque es lo que ella tiene interiorizado, que le da a los hijos y a la pareja, como si el hombre se fuera pero a la misma vez se quedara. 
Lo expresa de la siguiente manera:

"Después, de nuevo volví a pensar. Tengo que llegar a un acuerdo con él, para que mis hijos no sientan que su papá está lejos. Yo le dije, tú no te vas ir diciendo a tus hijos que te vas. Tú te vas ir, diciendo que te vas por trabajo por una semana. A la semana, vas a venir a ver a tus hijos. Normal yo esté o no ahí, tu ven a ver a tus hijos. Diles que estarían llegando a los ocho días de tu trabajo, sea Domingo o el día que te dan descanso. No les digas que te estás yendo. No vas a llevar nada de la casa. Así fue." (Diana, entrevista)

Quizás en sus hijos, la presencia de su figura paterna se ha llevado más en lo imaginario que en lo real, alentado por el discurso de su madre.

"Ellos han vivido, en verdad, ellos han vivido no sé cuántos años pensando que su papá trabaja lejos, y que viene una vez a la semana, el día que descansa, viene a estar con ellos." (Diana, entrevista)

Pareciera que Diana, no quiere renunciar a la idea de que su pareja le falle en el rol de su paternidad en el hogar, lo manifiesta usando a sus hijos como excusa pero la necesidad de tenerlo con una buena imagen en su representación mental es también de ella.

"Yo no tengo la culpa, tú demuéstrales que eres un buen papá. No importa que estés lejos, que tengas otra familia, demuestra que eres un buen padre. Estate en la sala con ellos, algo que ellos les guste, dales. Yo siempre le he dicho así. Ellos te van a entender, conforme van creciendo, te van a entender tu problema. Háblales, diles, lo que tú tienes." (Diana, entrevista)

Por otro lado, esta negación también ocurre con su familia:

"Yo nunca los hacía llegar, para que no vean mi problema. Siempre me preguntaban por él: “¿qué es de él?” “ahí está, todo bien”, “a ya que bien, ¿ahí está?”, "ahorita no llega de su trabajo”, cuando decían que les pase, para hablar con él: "no, no llega, llega en la noche”. Hasta esa hora, tenía apagado mi celular. Así los tenía." (Diana, entrevista)

Si bien era una manera de mantener a su familia alejados de la realidad debido a una fuerte vergüenza, por no haber cumplido con lo que se quería para ella desde 
pequeña, Diana podría haberse manejando en la mentira y de esta manera negar la ausencia de su pareja.

\subsubsection{Ser Mujer}

\section{En la casa: Donde existe lo mejor}

"Yo que te voy a decir... yo más te puedo hablar de mi casa ...en mi casa existe lo mejor...que son mis hijos, un alma mía, una alegría, en mi casa con mis hijos... tan lindo, encontrar, no puedes encontrar otra cosa más que no sea tus hijos." (Diana, entrevista)

Pareciera que desde pequeña le enseñaron a Diana el poder de la mujer desde el espacio privado. Las representaciones del rol de la mujer en el hogar se presentaban muy marcadas en su familia, Diana adoptaba el rol de madre de familia, y también se le pedía que lo hiciera. Mientras su padre se iba de hogar ella optaba por esperarlo, para que cuando llegue ella pueda atenderlo. Esto se puede ejemplificar en el siguiente relato:

“Mi mamá sólo ella se levantaba 7 de la mañana se levantaba y le decía “ ¿qué has preparado de desayuno?” - "ah tal cosa he hecho” - “ ¿tu papá se ha ido tomando?” - "sí, se ha ido tomando"- "ah ya”, así nomás. No pues como esposa ella debe tener la preocupación ¿no? "se va a trabajar, voy a prepararle”. Cuando él estaba tomando así de tiempo uy yo me levantaba, mis amigos me decían: "oye tu papá está con sus amigos, ha estado tomando, yo lo he visto han llenado un techo, no sé qué”, yo me iba a la casa de donde estaba, corriendo me iba, me ponía a prepararle caldo, un caldito, le ponía su huevito, su pollito, todo, un caldito pues, un caldo de gallina y le preparaba su olla y lo separaba, lo tenía listo. Ya cuando mi papá llegaba le servía su caldito y mi mamá "Ah qué, estás cuidando a este borracho, estás alimentando a este borracho, déjalo que se muera”. (Diana, entrevista)

Diana recibe un doble mensaje por parte de su madre quien primero le pregunta si ha atendido a su padre y luego la recrimina por estar "cuidando a un borracho" cuando ella le prepara el desayuno. Quizás se ve a esta figura masculina en dos plano: el proveedor que sale a trabajar y el borracho. Es como sí la madre le pidiese que 
"alimente" al proveedor y deje que "se muera el borracho". Parece ser que desde niña ha ido interiorizando que la función femenina es preocuparse por el hombre y servirle.

“Mi mamá lo veía... que nosotros seamos solo para la casa. Que el estudio no se ha hecho casi para las mujeres. Así me decía. Más seguro que estudien para mamá." (Diana, entrevista)

Diana comenta que su hogar forma parte de ella. Ante la primera intervención de la investigadora en la entrevista, manifiesta su amor por el espacio privado con la siguiente idea "el amor existe en la casa, con tus hijos".

También relata que cuando algo atenta contra la estabilidad de su hogar, automáticamente lo expulsa. Esto ocurrió con su ex pareja, cuenta lo boto de "su" hogar: "Así, fuera de mi casa.., Afuera lo bote" (Diana, entrevista)

Parece existir una especia de idealización que podría implicar someterse a un espacio privado que la espera y en el cual tiene que cumplir ciertas obligaciones, ahora no solo como pareja, sino también como madre. Se clarifica esto en la siguiente cita:

"Ya no quiero quedarme fuera de mi casa una hora más haciendo hora, por decir conversando, aunque sea de trabajo, cualquier cosa... me quiero regresar rápido... Sí, rápido pienso en mis hijas, tengo que llegar a hacer esta cosa, a decirles esto". (Diana, entrevista)

Es como si en su casa ella mandara y se posicionara en un espacio de comodidad.

Con el pasar del tiempo, si bien Diana ha pasado por experiencias que la han distanciado de su hogar para poder salir a trabajar y tener más autonomía en el espacio público, su hogar sigue siendo un espacio muy importante para ella. Pareciera que parte de la identidad femenina de Diana se encuentra arraigada al poder que tiene en su casa, en el espacio privado.

\section{En el trabajo: Amistad y autonomía}

“Mi hermano me dice ‘¿por qué tienes que trabajar en los trabajos de los hombres?' y yo le digo: Yo ya trabajo, ya salgo me voy a reuniones, tengo mis compañeros, no me voy a quedar lavándote. Tu quédate le digo" (Diana, entrevista) 
Diana comenta que luego de la desilusión amorosa que sufre, ha cambiado. Para poder proveerse a sí misma encuentra un nuevo trabajo y expresa su satisfacción por estar trabajando en construcción. Recordando a su padre, se comparándose con una cualidad de su padre.

“Ah sí, y mi papá era maestro de construcción y lo único que yo he salido a él, lo que me gusta lo que mi papá sabe hacer...Compartimos el mismo trabajo, ni uno ni más que otro... iguales." (Diana, entrevista)

Diana manifiesta que ahora ella tiene un rol activo en el espacio público, cuenta que esto la ha llevado a descubrir nuevas cosas, así como tener compañeros y socializar fuera del trabajo.

Al posicionarse y salir a espacios público tales como el trabajo y reuniones sociales, pareciera que Diana se va dando cuenta que la casa no es el único lugar de vinculación lo cual se puede apreciar en la siguiente cita añade:

“Así, en el trabajo, toditos se llevan conmigo, hacemos reuniones y todo (...) me extrañan cuando me mandan a otra obra y están que me llaman: 'cuando vas a regresar, cuando vas a terminar' me dicen y así pues voy conociendo un montón de gente" (Diana, entrevista)

Refiere que ahora siente poder desplazarse con mucha más autonomía en la esfera pública. Ejemplifica una situación en la que soñó con su padre y pudo irse "rapidito" a verlo, comprar su pasaje y emprender el viaje. Señala que esto recién lo ha podido hacer debido a su trabajo y las condiciones en las que trabaja. Lo narra de la siguiente manera:

"Oye, en ese rato he salido de mi trabajo, salí, me vine y me fui. Compré mi pasaje en ese ratito y como sea me fui. Asi rapidito, sin pedir ni permiso" (Diana, entrevista)

Resulta interesante que frente al abandono de la pareja, Diana va en busca de supervivencia para conseguir un trabajo y sostener a la familia. En este proceso, parece descubrir que puede establecer otro tipo de vínculo con sus compañeros, que van más allá de lo puramente sexual. La ganancia es que partiendo de una necesidad se termina posicionando como mujer en el espacio público. Da la impresión, que esto la reasegura sintiendo que no necesita de la pareja, porque ella puede salir a este espacio, trabajar y 
proveerse sola. Parece ser, que está incorporando a su identidad femenina el poder que puede tener en el espacio público encontrándose con una faceta suya que le permite conocer nuevas capacidades y disfrutes que puede realizar como mujer.

\subsubsection{Vínculo con la pareja: Idealizado, infantilizado, denigrado}

Diana cuenta que cuando conoce a su ex pareja, ella lo veía "todo bonito", sus ganas de tener "La mejor familia" pensaba que él era "el mejor hombre". Sentía que era lo mejor que podía tener para lograr una familia.

Cuando ocurre la infidelidad, esto le provoca mucho dolor y lo narra de la siguiente manera:

"Vivíamos bien... de la noche a la mañana, me derrumbé. Me dio estrés. Me encerré en un cuarto, en mi cuarto. Mi negocio, con todo puesto lo vendí. Lo liquidé... yo quiero cerrar todo. Dije no trabajo, dije no trabajo, no trabajo. Porque no quiero que me vea nadies, ni que me vaya a ver así, mal. Que me sienta triste. Mejor me encierro. Me encerré en el cuarto. Un mes sin salir, afuera. Solo, dormir, nada más, no tenía hambre." (Diana, entrevista)

Luego, cuando su ex pareja regresa a pedirle perdón Diana, firme en su posición, parece colocarlo en un lugar denigrado, como si él estuviese a su merced. Se muestra en el siguiente relato:

"Me dice si quieres mátame, si quieres mándame a la cárcel. Pero yo le digo que no, no lo voy a hacer las cosas ya están hechas, que agradezca" (Diana, entrevista)

Refiere que al conseguir un nuevo trabajo, sentía que lo que podía proveer el padre de sus hijos como hombre, ya no le servía para nada. Es como sí ella pasara a ser el hombre y denigrando lo que el pueda obtener económicamente:

“Como él no gana... tu sabes, fábricas es poco, en las ganancias, no hace bien las cosas. Si esto te ha pasado, qué vas a hacer, si está es tu felicidad, normal, te ayudare algún día en algo pues”. (Diana, entrevista)

En cuanto ella conoce a la mujer dice sentir "pena" por ella, por eso se posiciona en un lugar de madre, en el cual quiere "enseñar" a su ex pareja que hace con su nueva 
mujer. Lo trata como un niño, también convirtiéndose en su proveedora económica. Este aspecto se puede apreciar en la siguiente viñeta:

"Yo me sentí mal por la mujer. No tenía plata, él. Agarré y le digo por lo menos en esos años te vas a gastar ochocientos soles. Agarré ochocientos soles, le dije anda paga el hospital...yo le di. Anda paga el hospital. Sácala a la chica del hospital, así le tengo que andar diciendo" (Diana, entrevista)

Parece ser, que luego de la infidelidad existe un quiebre con la idealización del hombre y familia. Se transforma en proveedora y madre de la pareja que infantiliza y denigra.

\subsection{Caso Luz}

Luz es una mujer soltera de 30 años. Físicamente, es una mujer de contextura gruesa. Usa maquillaje labial de color rojo, peina el cabello recogido y usa ropa deportiva ceñida. Impresiona como una mujer segura de si misma con dominio de la situación.

Tiene tres hijos con la misma pareja, dos mujeres y un hombre en edades tempranas y adolescentes. Actualmente se encuentra separada del padre de sus hijos debido a una situación de infidelidad.

Nació en Chiclayo, fue criada por sus padres. Estudio secundaria incompleta y a los 17 años se mudó a Lima para acompañar a su hermana y buscar oportunidades laborales en la ciudad. Actualmente trabaja en una pequeña empresa de costura.

Refiere que desde pequeña, su familia la sobreprotegía y no la dejaban salir de la casa con amigas, porque según las reglas las mujeres, siempre debían estar en la casa y si salían debía ser casadas. Luz cuenta que desde que se separó del padre de sus hijos, se ha visto en la obligación de salir a trabajar para pagar el colegio de sus hijos y los servicios básicos de su hogar.

Se muestra dispuesta a colaborar con las entrevistas, desde el primer encuentro se muestra abierta a relatar su historia. Sin embargo, al hablar de su pareja muestra resistencias y demora en contar la historia de cómo vivió la separación. Se mantiene una conversación fluida, lo cual le facilita la recolección de datos a la entrevistadora. 


\subsubsection{Ser Hombre}

\section{Ser proveedor: el que cuida y sostiene}

Según refiere Luz, en su familia lo económico lo proveía la madre. Desde pequeña ella manifiesta como su padre se encargaba de otros aspectos tales como el cuidado y la seguridad de los hijos en la casa y en la escuela. Ella manifiesta que esto la llevo a tener una mayor cercanía afectiva con él. Aspecto que se puede apreciar en la siguiente narrativa.

"Sí, mi papá estaba en todo eso. Cuando yo estudiaba en mi colegio me apoyaba bastante. Mi papá más que todo, porque él andaba en chacra, tenía reuniones y mi papá asistía. En colegio, cuando necesitaban para cocinar, porque en el colegio cocinaban, mi papá iba a cocinar. Mi mamá no podía, porque como vendía en Chiclayo, no podía ir. Por eso, mi papá para todo, todo era para él: reunión, todo, el colegio. Todo era él. Mi mamá muy poco por lo que trabajaba." (Luz, entrevista)

Luz manifiesta que el rol de la madre era encargarse del sostenimiento económico del hogar mientras que su padre asumió el rol de regular las reglas al interior de la casa. Él se encargaba de darle permisos, acompañarlas cuando salía y cuidarlas del "peligro" de afuera a ella y a su hermana. Luz relata que solo la dejaban salir si era acompañada de su papa:

"Si yo quiero salir tengo que ir con mi papá. Así nomás no me dejaban salir, yo y mi hermana, las dos únicas que quedaban". (Luz, entrevista)

Recuerda también que las discusiones que se generaban entre sus padres eran porque el papá no aportaba económicamente lo suficiente. De niña Luz registra que su padre era muy criticado por su madre en su calidad de proveedor económico, reconociendo esto como único factor responsable de disputas entre la pareja parental. Este aspecto se hace relevante en la siguiente viñeta:

"Las veces que discutian era porque mi papá no tenía tanto trabajo y tenían que pagar luz, agua y eso. Y así pues, pero como mi mamá trabajaba a veces en su negocio de su pescado". (Luz, entrevista) 
Desde la narrativa de Luz planteada en líneas anteriores, paradójicamente sostiene que por un lado su madre cuestionaba a su padre en su calidad de proveedor pero a la vez le explicitaba su deseo de ser trabajadora y ella convertirse en la proveedora principal. Como observa en la siguiente cita: "vámonos pues yo también quiero trabajar, al menos te daré algo para que pagues".

Para adelante, esto se convirtió en una preocupación para Luz en el momento en que ella asumiría el rol de mujer adulta "Con verlos así, me preocupaba no. Luego se preguntaba como ella podía participar como proveedora económica desde el rol de hija, lo cual también le generaba angustia:

“De donde voy a sacar para poder ayudarles. ¿Qué voy a hacer, así será siempre? Ese era mi pensamiento... si mi papa no lo hace quien lo va a hacer... Así pensaba." (Luz, entrevista)

Más adelante, al conocer a su pareja en lima Luz cuenta que se enamoró y no pensaba fijarse en otra persona. No obstante, existía la preocupación que no fuera suficiente lo que trajera al hogar y lo evidencia en la siguiente viñeta:

"Me preocupaba eso no más que era un chico que ni trabaja, ni que voy a estar con él le decía, como él vivía donde su hermano... y a veces es así, le digo ¿porqué te cruzaste en mi camino y no otra persona, le digo. Qué será el destino, que me puso en el destino a él... pero también yo quería mi familia así... mis hijos no... como cualquier mujer, entonces ya pues ya así como para no fijarse en otra persona me quede con él.". (Luz, entrevista)

A pesar de estas preocupaciones refiere que primó el deseo de compaña, hijos y familia. Él fue proveedor de cariño y afecto, que Luz necesitaba en ese momento de su vida:

"No sé, yo como a él le digo: habrán sido tus palabritas que me hicieron así caer... será que estaba sola también, como por ahora, para mí que todos los hombres son así, le digo. Con tus palabritas, a veces, una mujer cae. A veces que le traes una florcita, un peluchito, la convences, le digo así de fácil." (Luz, entrevista)

Ella refiere que en ese momento sentía que necesitaba que le provean afecto, familia y seguridad, e indica que hoy en día respondería de una manera completamente 
distinta que en ese momento de su vida: "Ahora sí traes una florcita, le digo, regrésate con tu florcita, le digo. Regrésate con tu peluchito" (Luz, entrevista). Esta comparación que ella misma hace de un antes y un después, refleja la manera en que anteriormente Luz pensaba que su pareja debía proveerla de afecto y por eso se dejaba convencer, como sí en la pareja también buscara al padre. Actualmente pareciera que Luz mira estas debilidades que la hicieron enamorarse de él como algo distante.

También menciona que siente con mayor intensidad la ausencia de su ex pareja en momentos en los que se requiere arreglar cuestiones del hogar. Extraña una persona que le "resuelva" y la apoye en momentos de cansancio y tensión. Luz comenta que necesita esta presencia masculina que solucione los problemas que puede presentar, no necesariamente tiene que ser la pareja también puede ser otro hombre, lo relata en la siguiente cita:

"A veces cuando quiero para que me arregle la casa así, a veces tengo que llamarle, tengo que avisarle para que lo arregle. Sí, porque a veces yo, bueno, a pesar que su hermano también me dice: 'Cualquier cosa avisame, yo te puedo ayudar' pero claro, yo también tengo que avisarle a él para que venga a ayudarme también." (Luz, entrevista)

\section{Infiel: Sexo como prioridad}

En el caso de luz, cuenta que la infidelidad fue un punto de quiebre que la hizo pensar que la prioridad de su pareja era atender sus necesidades sexuales antes que sostener a su familia. Antes de esta infidelidad refiere que todo estaba estable con ella y su familia, salían juntos, compartían actividades y se encontraba "contenta" con su relación. Luz lo relata de la siguiente manera:

"Yo vivía normal con él ya, pero cuando yo salí gestando por mi última hijita como dicen se calentó la cabeza y se fue por allá pues; Me dejó cuando yo estaba de 6 meses de gestación por mi última bebé, pero asi son los hombres" (Luz, entrevista)

Al enfatizar que se "calentó la cabeza" podría estar haciendo referencia al deseo que le puede haber provocado su ex compañera de colegio (la mujer con la que le fue infiel) y como esto causó el abandono cuando ella estaba gestando a su último hijo. Luego el hombre pasa a ser una persona distante y poco constante con respecto a su 
relación, Luz señala "ya se ha ido... que viene a ver a sus hijos y deposita y asi". (Luz, entrevista)

En los años de adolescencia de Luz, ella comenta que ella observaba a su padre fuera de la casa mientras todas sus hermanas y su madre estaban en el hogar. Si bien a su padre nunca le han descubierto una infidelidad, en su imaginario su figura masculina estaba siendo infiel estando afuera del hogar, si bien no lo pensaba en el momento ahora le ha dado otro sentido a sus recuerdos. De esta manera, reflexiona en su discurso acerca de las actitudes de su padre:

"Mi papá se dedicaba a chacras. Cuando a veces no tenía tiempo, le tocaba sembrar así, se quedaba hasta la madrugada... para mí que ahi ha ido pensando en otra mujer ahora que lo pienso... de estar ahi en la calle horas y horas también se le ha calentado la cabeza pues, así." (Luz, entrevista)

Pareciera que Luz, re significa los sucesos de su propia historia en cuanto a su situación actual, lo cual podría ir transformando su manera de ver e interpretar su entorno y a las figuras significativas masculinas de su vida.

Refiriéndose a lo social, Luz relata que "todos los hombres ya son así...sexo nomas buscan... por eso mienten también... todo se mueven por eso". Frente a esta nueva representación, nos manifiesta su temor a volver a tener una relación lo cual es un impedimento para que pueda re hacer su vida, lo cuenta de la siguiente manera:

"Ya como yo tengo que he vivido con él, ya yo pienso que ya todos los hombres son así. O sea yo tengo miedo de formar otra asi de meterme con alguien que digo de repente me va a dejar así nuevamente ilusionada”. (Luz, entrevista)

Luz relata que este miedo también está presente en la relación con sus hijas. Cuando ellas le cuentan que tienen nuevas amistades masculinas dice tomar una actitud alarmista y transmitirles el mensaje a sus hijas de que en los hombres manda la sexualidad y que esto podría hacerles daño. Al escuchar el relato de sus hijas, ella le responde:

"No tengas tanta confianza con los vecinos. 'No que estoy conversando me dice' Si hijita, pero tú sabes que los vecinos se pasan. Agarro y le digo que los vecinos son unos mañosos sabes que puede pasar algo, le digo”. (Luz, entrevista) 
Refiere que esta manera de responder, da cuenta del temor que le genera la posibilidad que un hombre pueda mostrar su deseo sexual ante su hija, y que de esta manera ella salga dañada. Repitiendo un poco los sucesos de su historia, Luz no quiere dejar a su hija sola, la siente vulnerable:

"Por eso a veces, tengo miedo de dejarlo a mi hija. Mi hija a veces se queda sola en las mañanas. Yo le digo que no me abra la puerta hijita. Cuando tocan la puerta, por la ventana. Pregunta quién es, y tú mamá no está. Pero no me abras la puerta para nada." (Luz, entrevista)

Resulta interesante que al igual que su padre cuando ella era pequeña, Luz toma la misma actitud que su padre con ella cuando era adolescente, e incluso comparten la misma preocupación que se pueda “inquietar". Esto se aprecia en la siguiente viñeta:

"Como mi papá veía que yo salía con mi vecina del costado 'no que a veces llega tarde, que de ahi se va al baile... no quiero que de ahí se inquiete nuevamente' decía." (Luz, entrevista)

Parece ser que el miedo se ha instalado al interior de Luz, desde la sobreprotección de su padre tiene influencias en la manera que está criando a sus hijas. El hombre puede ser por Luz visto como una fuente de "inquietud" y fuente de daño de la cual hay que cuidarse.

\section{Pseudopresente: El que no deja olvidar.}

"[le dice a la ex pareja] Yo pienso en ti, crees que tú con decirme 'ya, que ya lo voy a hacer' se arreglar todo? no me dejas olvidar, ya si te vas...te vas pero no me estés haciendo pensar así le digo. Tú más dices palabras, yo no quiero palabras, si ya siempre me has dicho lo mismo y no hay cuándo le digo. Así me quedo pensando y esperado y no hay cuando... así no es" (Luz, entrevista)

Luz comenta que debido a las promesas de este y la expectativa que ella tiene a que el finalmente cumpla sus promesas, no logra olvidarlo y lo tiene constantemente en su pensamiento.

Al principio, ella también intenta mantener la imagen de su padre presente en el pensamiento de sus hijos. Cuenta que a pesar que el "se retiró" él no quería que sus hijos se quedaran sin padre, por eso tuvo que comenzar a mentirles para que "no se den 
cuenta". Luz manifiesta que no deseaba que sus hijos se enteren de la situación que ella pasaba con su pareja y que pronto su padre volvería: "A mis hijos les decía, 'tu papá se queda en su trabajo, ya llega', así le decía para que lo tengan presente" A partir de la ruptura con el padre de sus hijos, Luz parece tenerlo más presente en el imaginario que en lo real.

Más adelante, Luz comenta que "siempre lo esperaba para que cumpla lo que decía". La manera en que espera lo que la ex pareja prometía es una manera en que ella se queda a la expectativa de él. Le cuesta dejar de esperar, y esto implica que lo tenga presente aunque esté ausente en la vida cotidiana de luz.

\subsubsection{Ser Mujer}

\section{En la casa: Donde esta la seguridad}

Recorriendo la historia de Luz, nos cuenta que en su hogar primaba la costumbre que la mujer debe estar en el hogar, y en el momento que sale ya se tenía que ir casada. Cuenta que no existía un punto medio en el cual la mujer también pueda salir y tener poder en el espacio público. Solo salía a este si estaba acompañado por una figura masculina, en este caso su padre: "Si salgo, saldré con mi papá, les digo, porque así sola no me dejan salir." Esta actitud trasmite un mensaje en el cual el padre le hace entender que territorio de seguridad es en el espacio privado, su hogar. "De mi casa no me dejaban salir...nada... Así era: de mi casa, de colegio a mi casa. Así andaba segura mejor".

Ante la negación de salir, Luz refiere que comienza a incorporar el deseo de estar en casa y alejada de la vida externa, que lo hace suyo y comienza a gustarle quedarse en su hogar "A veces a mí tampoco no me gustaba salir (...) mejor estaba en mi casa. Yo cuando vine acá a Lima, no era de salir..."

La importancia de permanecer siempre en el hogar, puede haber sido trasmitido desde la historia de la madre. Luz cuenta que a su madre la "casaron por salir". Comenta que la posibilidad de tener una participación activa en el plano privado y público no era posible. Nos cuenta de esta manera la historia de su madre:

"Allá en el Norte, es de que, ya bueno, tú no llegas a dormir una noche a tu casa es porque ya te saliste o saliste embarazada. Eso era antes allá. Mi mamá dice que salía y salía, una fiesta, y porque mi mamá se fue a dormir a la casa de una amiga y mi abuelita pensaba que se había ido con hombre, que se había 
salido. Mi mamá dice que regresó en la tarde todavía, porque tenía miedo y mi abuelita le pegaba...y de ahí por eso la han hecho casar, porque se ha salido de la casa". (Luz, entrevista)

Por parte de las historias familiares y la actitud hacia el espacio público en el hogar, predominaba la idea que una como mujer tenía que estar en la casa, que ese es su espacio, y salirse de éste tenía consecuencias serias. Esta creencia ha podido influir en la identidad de Luz, que parece incorpora el espacio privado como significado de deber y seguridad.

También es en este ambiente donde Luz comenta tener poder y autoridad. Contempla su casa como un espacio privado y cuando ocurrió la infidelidad de su pareja, resalta la invasión de la otra mujer en su hogar y la manera en que expulsó a su pareja del espacio privado. Lo primero que hace Luz ejercer su poder para expulsarlo de este espacio, de esta manera:

"Más rápido lo boté de ahí: 'Vete de acá' le dije así. No sé, yo le dije a él: 'Vete con ella; le dije así, 'vete de mi casa' le digo." (Luz, entrevista)

Cuando viene la otra mujer a reclamarle, cuenta que lo primero que le impacta es que haya irrumpido en el hogar, lo expresa en la siguiente viñeta:

"Vino pues a reclamar, y a mi casa. Con que derecho, ella no tiene ni un derecho de venir a reclamarme a mi casa, mucho menos cuando están mis hijos, le digo." (Luz, entrevista)

En esta narrativa, Luz se posiciona y manifiesta sentirse dueña del espacio del hogar asumiendo todo el derecho y el poder sobre él, ella decide quién se queda y quien sale.

Cuenta que actualmente, a su hija también le inculca la importancia del espacio privado e intenta controlarla mediante este. Estar dentro del hogar, la podría proteger de cualquier amenaza, especialmente de la sexualidad del hombre, como ya se explicó anteriormente. Cuando la hija se va con sus amigos, o conversa con algunas personas de su entorno, luz siente una necesidad inminente para protegerla y reacciona de la siguiente manera "cada vez que pasa el vecino: "Hola vecino”. Como que no, un poco que le... Y el vecino también se para a conversar. Le digo 'ya Nilda a tu casa adentro' le digo." Cuando su hija se asoma al espacio público Luz le llama la atención de la 
siguiente forma "Tienes que meterte a tu casa ya. Cualquier cosa puede pasarte, para que vas a ir, ahi es donde mas segura estas"

Parece ser que a lo largo de su historia, ha ido interiorizado la idea de que el poder y la seguridad parte de su identidad femenina se condensa en el espacio privado del hogar. Si bien se encuentra trabajando y tiene mayor posición en el espacio público, no renuncia a su poder en lo privado, beneficiándose de la autoridad que este le otorga también para criar a sus hijas.

En el trabajo: Oportunidades e independencia

"Comencé a trabajar...me entré a esa empresa, me aseguraron porque te aseguran 1 año. Duré 1 año en esa. Fin de año para navidad y año nuevo me dieron mi grati, con eso tuve la oportunidad de comprarles también ropa a mis hijos. Ahí sí, porque con la miseria que él me daba no me alcanzaba para nada." (Luz, entrevista)

Luz narra que a partir de la separación con su pareja, ella comienza a salir a la calle para trabajar y proveerse a sí misma y a sus hijos. Ante la ausencia del padre de sus hijos, ella comienza a "rehacerse" a sí misma y otorgarse la satisfacción de poder ser una mujer proveedora, lo cual implicaba no querer nada de la ex pareja, todo esto comienza cuando ella empieza a trabajar y tener contemplarse como independiente de la pareja:

“Claro, o sea yo ya no quería nada con él, yo no quería nada ya. Porque bueno yo empezaba a trabajar ya...como rehaciéndome también”. (Luz, entrevista)

Al usar la palabra rehaciéndose, da la impresión que la manera en como ella se piensa y concibe se encuentra en un proceso de cambio, debido a sus nuevas interacciones con el entorno.

Parece quererle demostrar que ella también tiene una posición en el espacio público y esto la hace sentirse más empoderada de su misma, quizás de esta manera ella también se está posicionando en un lugar donde puede rechazarlo:

"Lo llamaba cuando había bulla. Y me decía “¿dónde estás?” le digo: “ ¿a ti que te importa?, tú nomas mándame” le digo" "para que de una vez... ahorita estoy ocupada" le digo "no te puedo seguir conversando" le digo." (Luz, entrevista) 
Según lo que cuenta Luz, su ex pareja no desaprovechaba la oportunidad para hacerle sentir que su lugar estaba en a casa con sus hijos. El padre de sus hijos, le trasmite la idea de que ella tiene que estar en el hogar cuidando de sus hijos, cree que el salir a la calle implica involucrarse en una relación con otro.

"[el padre de sus hijos] Me dice sí, que de repente que como yo estoy trabajando no vaya a abandonar a mis hijos, no me vaya descuidar de mis hijos, 'no te vayas a meter con alguien, tú tienes que ocuparte de los hijos' (...) pero si yo te estoy pasando plata" (Luz, entrevista)

Luego de ella poder sentir que como mujer ha tenido la oportunidad de salir a la calle y proveer a su hogar, manifiesta el sentimiento de haber cambiado, en especial en la manera en que se relaciona con su ex pareja. Cuenta que ella le dice a su ex pareja:

"Te das cuenta que así te vayas o así te quedes igualita soy yo, ahora ya yo ya no soy la de antes", le digo "ahora ya he cambiado" (Luz, entrevista)

Con respecto a las funciones de su pareja como padre, Luz menciona que se ha visto obligada a cubrirlas todas debido a la ausencia del padre de sus hijos. Ella se ha convertido en el pilar del hogar, comentando que siempre está al pendiente de todas las necesidades de ella y de sus hijos. Lo cuenta de la siguiente manera:

"Por los tres pago el colegio, a pesar que mis hijos están en estatal pero es como que estuvieran en un particular. Pago la luz, el agua, se termina mi gas, todo. Y yo tengo que estar ahi pagando de mi trabajo, la miseria que me da no me alcanza" (Luz, entrevista)

Parece ser que en este momento ella ya no quiere nada de él porque ya se provee a ella misma señala porque ya comienza a trabajar. Podría estar posicionándose como posiciona como la principal proveedora y por ende la que tiene el dominio en el espacio público. 


\subsubsection{Vinculo con la pareja: Infantilizado, denigrado.}

“[Luz hablándole a su pareja] Déjate de tonterías ya... ¿hasta cuándo vas a sentar cabeza ya?, ya no tienes ni 17 ni 18, ni 20 años, ya tienes ya pues, ya vas a entrar a la etapa 40, ya la etapa 4 ya debes madurar" (Luz, entrevista)

Luz cuenta que luego de separarse del padre de sus hijos, ella "le hablaba". En su relato, enfatiza que ella no entendía cuando él iba a comenzar a ser responsable. Quería instruirlo para que él pueda cambiar. Se puede dar cuenta de esto en la siguiente cita:

"Ya no sé qué hacer para que entiendas... ¿Hasta cuándo vas sentar cabeza?, tú decídete dónde te vas a quedar: aquí o allá" porque mira, no te voy a poder tener así acá por siempre” (Luz, entrevista)

Da la impresión, que Luz menosprecia lo que él puede darle a sus hijos: “con la miseria que él me daba no me alcanzaba para nada." Cuenta que ella pensaba que el "aparte de irse con otra no sabía hacer nada en el negocio". Al expresar esto, la entrevistada cree que el padre de sus hijos no es útil, no le provee lo necesario ni a ella ni a sus hijos por eso refiere que el "está de adorno no más".

Pareciera que también lo infantiliza en cuanto a lo que él puede proveer e inclusive se queja con su madre de el con respecto a la conducta del padre de sus hijos. Luz cuenta que fue a hablar con su madre a ver si "algo cambiaba". Dando la impresión, que la madre pudiese corregirlo en ese sentido

"Pero, ¿qué voy a hacer señora?” le digo "si su hijo ni siquiera me viene a dejar, me deja una miseria que ni siquiera a mí me alcanza, eso es lo que quiere, que lo denuncie. Usted diga le algo así.”. (Luz, entrevista)

Luz también manifiesta sentirse responsable acerca del rol paternal que su ex pareja no está ejerciendo con sus hijos, comentando que el necesita la presión externa para cumplir con sus obligaciones, lo que también sugiere la manera infantil en que lo percibe:

"Porque de todo lo que yo he hecho para que él se preocupe más por sus hijos un poco que está así ah, sino no hace nada él, sino no hace nada." (Luz, entrevista) 
Llama la atención, la actitud de Luz frente a la pareja. Al principio lo denigra, menospreciando todo lo que le da y lo que hace, pero luego adopta una posición de madre en la cual lo infantiliza, queriéndolo instruir, dominar y cuidar.

\subsection{Caso Berta}

Berta es una mujer de 36 años. Físicamente, es una mujer de contextura delgada. No usa maquillaje, lleva el cabello recogido en una trenza y usa ropa formal durante la entrevista.

Estudió secundaria incompleta. Es soltera, tiene una hija de 6 años y actualmente se encuentra separada del padre de sus hija debido a al abandono de su pareja por causa de una infidelidad.

Nació en Cajamarca donde vive hasta sus 16 años con sus padres. A esa edad migra a Lima porque quería olvidarse del enamorado con quien acababa de terminar una relación. Llega a Lima a vivir a la casa de sus hermanos. Luego que termina la relación con el padre de su hija, comienza a trabajar como empleada doméstica cama afuera.

Recuerda que sus padres solían no esta de acuerdo con las relaciones de pareja que ella tenía y opinaban sobre su vida amorosa. Relata que su familia se volvió inestable cuando el padre le fue infiel a su madre. Berta comenta que desde que se separó del padre de su hija, ella ha sido el único pilar de su familia y no ha pensado en volverse a enamorar.

Se muestra dispuesta a colaborar con las entrevistadora, desde el primer encuentro se muestra abierta a las intervenciones. Sin embargo, al hablar de sus relaciones amorosas y de la vida cotidiana con su hija, interrumpe el discurso con llanto.

\subsubsection{Ser Hombre}

\section{Ser proveedor: El que da el dinero}

En el hogar de Berta, el proveedor económico siempre fue el padre. Cuenta que la relación entre sus padres se sostenía en base al dinero que traía su padre al hogar. Añade que si bien su padre fue infiel, siempre se hizo cargo del sostenimiento económico del hogar. Esto se puede apreciar en la siguiente narrativa:

"Mi papá trabajaba, lo que él ganaba le daba a mi mamá pero qué pasa, que había problemas porque mi papá empezó a sacarle la vuelta a mi mamá. 
Entonces ahí era el problema porque mi papá venía de viaje, como trabajaba llegaba una vez a la semana, dos veces a la semana, entonces se...empezaba la pelea con mi mamá, pero a mi mamá ya con lo que le mantenía, un poco que la calmaba cuando traía la plata.". (Berta, entrevista)

Berta comenta que desde pequeña su madre le inculcaba la idea de que el hombre la debía de proveer económicamente. Cuenta que cuando se enamoró por mi primera vez, su madre no aprobaba la relación ya que él no tenía como mantenerla en un futuro. Lo expresa en de la siguiente manera:

"Yo me enamoré cuando tenía creo que dieciséis años... me iba a casar ahí pero cuando los papás no, no quisieron, no se pudo. Mi mamá no quiso, y ahí ya pues, nos alejamos" (Berta, entrevista)

Berta señala que la razón predominante para la desaprobación de su madre era la preocupación que la pareja no tuviese suficiente dinero. Esto lo "desmerecía" en su capacidad con ser proveedor suficiente sostener económicamente a su hija. Refiere que cuando su madre se expresaba sobre su enamorado decía:

"Dice porque no valía la pena... él trabajaba, pero será porque era joven, no sé... pero vivía con sus papás. Entonces como ella decía 'no te vas a ir con él, y donde vas a vivir... de qué te va a mantener' En eso se basaba” (Berta, entrevista)

Pareciera que el entorno de Berta quería "algo mejor para ella", lo que se traducía en un hombre con poder económico que la pueda proveer en el futuro de la misma manera que los padres lo venían haciendo con ella.

La madre enfatizaba su postura y alentaba a que Berta estuviese con otros hombres que pudieran ofrecerle la seguridad económica que ella esperaba para su hija. Sin embargo, Berta señala que el criterio de elección de la pareja, para ella no estaba centrado en el sostenimiento económico, situación que fue generando varios desencuentros en la relación con su madre. Recuerda que la madre, le proponía que aceptara a un chico que tenía dinero porque con él no "se iba a morir de hambre":

"Es que había otro chico que era, económicamente muy diferente a los otros. Es que estaba bien económicamente, y entonces como que este chico si mi mama lo quería, Entonces mi mamá me decía 'con él no te vas a morir de hambre' Yo le 
decía 'a mí no me interesa él' y entonces como que ahí era el dilema”. (Berta, entrevista)

Al pasar los años, Berta continuaba convencida de que erigiría a una pareja que le de afecto y cuidado. En Lima, se enamora de un hombre que desde su perspectiva reunía las características de ser proveedor de seguridad, cuidado y afecto. Señala que esto la llevó a enamorarse del padre de su hija. Como menciona en la siguiente narrativa:

"Él fue militar, tiene carácter, paraba siempre pendiente de mi y lo que necesitaba. De ahí me enganchó” (Berta, entrevista)

Si bien pareciera que no busca únicamente un proveedor económico, se percibe que Berta buscaba un hombre que la sostenga, que le brinde seguridad y la cuide. Puede ser que el valor de "proveedor económico" signifique para ella ser un "proveedor de seguridad". Finalmente Berta elige como pareja a un hombre militar, autoridad como la madre y el hombre proveedor que la madre deseaba para ella.

Frente a su dilema interno de seguir el mandato materno de elegir a un hombre que la mantenga o rebelarse y elegir un hombre que este "pendiente de ella" y cubra "lo que necesitaba". Termina resolviendo, de manera inconsciente, el dilema identificándose con el deseo de la madre porque luego que tiene a su hija y se separa, ella le reclama que reconozca legalmente a su hija y exige sus derechos de manutención porque ella no los podia asumir.

Luego que la pareja la abandona y Berta se queda sola criando a su hija, ella busca protección en sus hermanos. Cuenta que hasta el día de hoy estos la "cuidan" y comenta sentirse protegida por ellos:

"Mis hermanos así son dicen: 'Sí que no sales, a qué hora llegas? con quien sales?'. Así son. Hasta el día de hoy son así. Por ejemplo, salgo del trabajo y mi hermano me dice 'ya saliste?', eso a mi me hace sentir protegida digamos, aunque sea ellos están ahi." (Berta, entrevista)

Mas adelante, la relación con el padre de su hija se vuelve puramente económica. A pesar que el comienza a alejarse, Berta se centra en lo económico y esto se convierte en el único motivo para estar con él, cuando ya la relación entre ambos se había deteriorado. 
"Ni lo veía sabes, solita yo iba a ver el terreno que iba a comprar para construir, el me estaba dando la plata para construir. Ese terreno lo compré yo con dinero que tenía, y él me daba el dinero para construir y vivir, se suponía. Ya esa era nuestra relación." (Berta, entrevista)

Resulta interesante cómo Berta, al igual que su madre, mantiene una relación con la pareja basada en la protección económica que le pueda brindar.

\section{Infiel: Siempre habrá otra mujer}

"Se insultaban, se insultaban y una vez se fueron a las manos. Entonces si...mi papá le gritaba a mi mamá, mi mamá le gritaba 'seguramente por estar con esa perra, con esa puta'. Siempre ese era el problema, que se paraba acostando con muchas". (Berta, entrevista)

Berta crece en un hogar, donde pareciera que la infidelidad del padre era uno de los aspectos que predominaban en el hogar. Comenta, que su padre se acostaba con "muchas" y esto generaba disputas con su madre, pero aún así no planteaban la posibilidad se separase. Cuenta que su padre, al estar afuera del hogar tenía relaciones sexuales con varias mujeres.

Cuando Berta elige su pareja, rescata el hecho que el no la "cogiera por la fuerza". Pareciera que tiene la creencia que eso "hacen los hombre", y de esta manera manifiesta sentirse afortunada que su pareja nunca la forzó.

Mas adelante, Berta reflexiona acerca de la relación con su ex pareja, tratando de encontrar un motivo para su infidelidad. Pareciera otorgarle esto a sus cualidades de "macho" que interesantemente en un principio fueron las que la enamoraron. Esto se hace evidente en la siguiente viñeta:

"Él era así todo macho como dicen, por eso abra tenido también la otra familia Él siempre andaba, la forma de caminar era bien antiguo, que quizás era por el ejército. Además tenía carácter de voz de mando, que era algo que siempre me llamaba la atención. A todas las mujeres quizás, por eso el iba acostándose con sabe dios cuantas" (Berta, entrevista)

Estos sucesos, parecen reiterar la construcción infantil que tiene Berta de los hombres, rescatando siempre la característica de infidelidad, generalizándola para todos 
los hombres. Al parecer esto provoca un temor en Berta que la hace sentirse decepcionada acerca de sus actuales y posibles relaciones.

"Yo decía no es justo que me vaya a...conocer a un chico que te va a decepcionando y como que decir ya...siempre decía creo que tengo muy mala suerte, muy mala suerte, todos los hombres son así... mentirosos, te engañan tiene sexo y familias con otras" (Berta, entrevista)

Finalmente, comenta que existen muchas diferencias en como vive una mujer y un hombre:

"Aunque ser hombre, siempre he dicho tiene más libertad o cuando asistías a un adolescente tiene más libertad, en un momento claro que decir me gustaría ser hombre para tener una y otra chica o que nadie me prohiba si estoy con tal persona, tal persona ¿no? esa es la diferencia para mi, no puedes así ni tener sexo." (Berta, entrevista)

Rescata como característica fundamental, el tener hecho de tener muchas parejas la libertad de tener sexo, viendo esto como algo limitado en ella por el hecho de ser mujer.

\section{Pseudopresente: Querer a quien se va.}

"Todo el tiempo que se fue me dejaba pensando en él. Decía que lo hacía por el bien de nosotras, la bebé y mío. Porque le van a pagar mejor. me hizo abrir un número de cuenta, que nunca me depositó un sol". (Berta, entrevista)

Berta comenta que luego de la ruptura con su pareja, la vivencia de la relación pareciera tener mas peso en lo imaginario que en lo cotidiano. Relata que siempre lo tenía presente aunque el no esté, debido a promesas y expectativas que este realizaba.

Berta recuerda que experimentaba las promesas como certeras y señala que esto hacia que no pudiese olvidarlo, debido a estar siempre esperando su regreso. Pareciera que en el imaginario todo era semejante a la realidad y pensar en un posible engaño por parte de la pareja era intolerable para ella: "No sé cómo es posible... no sé si me mintió tanto, parecía tan real, yo lo crei"

Mas adelante, Berta manifiesta tener la creencia que le gustan los hombres que van a estar ausentes, que no van a poder sostener una relación constante a largo plazo. 
Pareciera que su imagen del hombre como pareja se caracteriza por la ausencia y el abandono.

“El sí me gustó, pero de repente soy yo, a mí me gusta creo que esos chicos que te van a dejar, como dice mi hermano que te deja y te dejan que se van y no están." (Berta, entrevista)

\subsubsection{Ser Mujer}

\section{En la casa: Donde están los deberes}

Berta recuerda que de niña era muy sobreprotegida en su hogar. Cuenta que no la dejaban salir si no estaba acompañada. Señala que esto la hacia sentir "insegura” en el espacio publico, y por eso refiere que su zona de comodidad era su casa. Comenta que la compañía de su madre era imprescindible para salir. Esto se puede apreciar en la siguiente cita:

"Te ibas a una fiesta, te invitaban a una fiesta, ella tenía que ir contigo, si no, no ibas. Ay eso me molestaba a mí porque yo decía ¿por qué es así si mis amigas se van sin mamá? Me decía ah entonces si no, no vas. Si tocaba ir de viaje de promoción, tenía que ir ella que si no, no podía ir yo sola... nunca fuera de mi casa" (Berta, entrevista)

Con respecto a las labores domesticas Berta cuenta que su madre siempre le enfatizó la importancia de tener el dominio de todas las actividades que se realizaban en el hogar. Refiere que la madre le quería "meter la idea" de que sus hijas siempre tenían que estar en el hogar y ser muy buenas amas de casa. Eso se ve reflejado en la siguiente narrativa:

"Yo tenía once años, no sabía cocinar, me agarraba de los pelos en la cocina, me decía 'ah para que tengas enamorado eres buena y para cocinar no puedes, ¿no?’ o si no me decía que lave y si no lavaba bien, me daba con lo que encontraba, si así era.. nos decía que siempre teníamos que cumplir los deberes en la casa" (Berta, entrevista)

Posteriormente, cuando Berta conoce al padre de su hija y se muda con el, refiere que su lugar siempre estaba en el hogar. Recuerda que pasaba sus días "metida en la casa" esperando que su pareja llegue del trabajo. Sin embargo, antes de la 
infidelidad Berta recuerda los momentos que pasa en su hogar como muy felices, como se percibe en la siguiente cita:

"En mi casa yo era feliz, era mi mundo. El cuando estaba ahí Nunca me gritó, nunca me levantó la mano. Al contrario, hasta el último me decía que me amaba. O los mensajes, cuando se iba a trabajar... me decía que te amo, que te extraño, yo era feliz así en mi casa." (Berta, entrevista)

Luego de la situación de infidelidad, Berta pareciera muy preocupada con respecto a tener que dejar su casa. Al parecer, su situación se había salido de control e iba a tener que salir del hogar. Berta reflexiona sobre los pensamientos y sentimientos desagradables que le daban al enfrentarse a esta situación de la siguiente manera:

"En un momento como que yo pensé tener una vida entera con él pero después yo veía y decía si me voy con él ¿de dónde me va a dar para comer?, o sea que yo siempre pensaba dios mío ¿cómo va a trabajar?, me va a matar de hambre” (Berta, entrevista)

Pareciera que lo mas le preocupa es no poder sostener a su hija y "darle de comer". Es como sí le hubiera atribuido únicamente la cualidad proveedora a su pareja. Están en esta situación la lleva a reformular su idea de "ser mujer", y a la vez desmitificando que cualidad proveedora fuera exclusiva del hombre.

\section{En el trabajo: tomar el control de su vida}

Conforme pasó el tiempo pareciera que Berta tomó el control de su vida e inclusive rechaza la ayuda que le quiere dar el padre de su hija. Cuenta que ante todo el "resentimiento" ya no quería "nada de el", y por eso iba a mantener sola a su hija. Lo cuenta en la siguiente cita:

"Me quiso dar plata, no le recibí y le di mi hija a mi mamá. Me dijo que no estaba nada bien que seguía con problemas con la señora de miércoles, haciendo problemas con las niñas Le dije que no me interesa y ahi nomás me quité yo.." (Berta, entrevista)

Pareciera que Berta pasa de una total inseguridad con respecto al poder mantener a sus hijas a una posición en la cual ella se empodera como principal proveedora del hogar. Esto se aprecia en la siguiente cita: 
“Tuve a Lya y ya pues como que, me pegó y mas que no hay el papá. yo ya soy mama tengo que mantener la casa salir a buscármelas" (Berta, entrevista)

Ahora su deber también esta en el espacio público, para poder mantener a su hija y ser el pilar de la familia. Ella luego manifiesta su cambio de la siguiente manera:

"Sí, después cambié. Yo decía que así sea el último hombre en la tierra nunca me metería con él." (Berta, entrevista)

Resulta interesante como Berta pasa de pensar que necesita al hombre hasta para "comer" y luego de un tiempo de la partida del padre de su hija, toma otra perspectiva y parece sentirse capaz de rechazarlo y de mantener a su hija.

Cuenta que en la actualidad, se siente "libre" menciona también actividades en el espacio publico.

"Ahora es diferente... por ejemplo si Había una fiesta o mis hermanos a veces iban, ellos nos encontrábamos, ellos allá en la fiesta y yo de acá cogía un taxi y me iba, once, doce de la noche llegaba hasta las seis de la mañana amanecías en el baile y de ahí agarraba el carro, los chicos...mis hermanos a su casa, mis amigas también cada quien a su casa y yo al trabajo." (Berta, entrevista)

Quizás la infidelidad de la pareja, ayuda Berta para encontrarse con aspectos desconocidos de ella misma. Esta situación parece haberla retado y al sobresalir y cumplir tareas que percibía como "masculinas" se comienza a pensar de otra manera.

\subsubsection{Vínculo con la pareja: infantilizado e idealizado}

Cuando Berta conoce al padre de su hija, menciona que tenía muchas expectativas acerca de formar una familia con el. Menciona que ella pensaba en un futuro juntos y quizás eso la hizo "cegarse” ante las infidelidades de su pareja.

"Yo sí quería tener hijo. Pero yo no podía salir embarazada. Quería que el fuera el padre de mis hijos. Hasta tal punto que no se, me loquie, ya no miraba nada más" (Berta, entrevista)

Pareciera que ante el deseo de tener hijos una familia, Berta pudo haberlo idealizado. Como lo dice en su propio discurso "para mí era el hombre perfecto" 
Incluso comenta que cuando se entera de la infidelidad, ella niega estos hechos y lo acompaña al juzgado para enfrentar las denuncias de la otra mujer. Señala que mientras el estaba a su lado, ella "todo le creía". Berta refiere que ella creía ser especial para su pareja, y por eso no le importaba que la otra mujer lo haya denunciado.

"La chica lo llegó a demandar, yo lo acompañé para que pase por el examen psicológico por haberla golpeado, porque dice que sí la había golpeado. Yo nunca la vi a la chica. Pero conmigo nunca fue asi"” (Berta, entrevista)

Cuando comenzaron los problemas y la pareja se comenzó a ausentar, Berta seguía creyendo en el ideal de familia y por eso se quedaba a la espera de él. Es posible, que se siguiese dando una idealización, debido a las ganas que tenia de lograr el sueño de compartir una vida con el:

"Si pues, estaba dolida, y por eso seguí saliendo con él. Se supone que: íbamos a tener una vida juntos". (Berta, entrevista)

Luego, cuenta que "Se desapareció sin decirme nada. Ya no llegó a la casa." Pareciera que este hecho la confrontó con la realidad del abandono de su pareja. Lo cuenta de la siguiente manera:

"Yo si llegar a confiar ciegamente en él. No llegaba, porque me decía que todavía estaba en el trabajo. Empecé a llamar a partir de las doce de la noche, y apagado. Una de la mañana, dos, amaneció y nunca llegó. Nunca más llega, de verdad." (Berta, entrevista)

Parece ser, que si bien la pareja pudo dar señales de estar alejándose y de estar siendo infiel Berta no quería confrontar esto. Podría ser que tenía una idealización tan fuerte que no le permitiera ver los hechos reales, lo cual la retaría también a ver diferentes aspectos de ella como mujer.

Luego del abandono, Berta cuenta que a pesar de su ausencia lo seguía queriendo. Sin embargo, hubo un punto de quiebre que fue el tener a su hija sola. Esto la hizo reaccionar y pareciera que comenzó un proceso de des idealización. Berta lo explica de la siguiente manera:

“Mira yo a él lo quise muchísimo, hasta que di a luz. Desde que di a luz para mí ya fue, porque me dolía tanto." (Berta, entrevista) 
Pareciera, que Berta pasa al punto de denigrarlo, cuando su ex pareja no quiere reconocer a su hija. Podría ser que ella pudiese perdonar lo que le hicieran a ella, pero en su rol de madre no podría, llegando a "odiar” a alguien que perjudique a su hija.

“Cuando él ya no estaba conmigo, lo odié. 'Imbécil tu qué crees que mi hija no merece llevar tu apellido'. Ahi Me di cuenta. 'Ella va a llevar el apellido tuyo le digo... Te vas a arrepentir toda tu vida.' Ahí, corté comunicación con él." (Berta, entrevista)

Actualmente, el discurso de Berta plasma la denigración de su ex pareja. Se puede notar que de una total idealización se paso a una denigración, que muestra un posible mecanismo en la forma de vinculación de Berta. Se hace evidente en la siguiente viñeta:

"Cuando él esté como el perro por ahí, y que no tenga a nadie, seguro va a ir donde mi hija y lo que es de mí le digo así lo vea muriendo nunca le voy a dar un vaso de agua" (Berta, entrevista)

\subsection{Caso Carmen}

Carmen es una mujer de 21 años. Físicamente, es de contextura delgada, pelo ondulado de tex trigueña y estatura baja. Aparenta menor edad, durante la entrevista mantiene un tono pausado y en varios momentos su discurso se acompaña de llanto.

Estudió secundaria incompleta. Es soltera, tiene una hija de 5 años de edad y actualmente se encuentra separada del padre de su hija debido a una infidelidad.

Recuerda que sus padres no tenían ninguna relación, solo menciona que su madre le contó que se habían separado a causa de una infidelidad cuando ella estaba gestando. Recién conoce a su padre a los 15 años, estableciendo una relación distante con el debido a que este tiene otra familia. Enfatiza que sus padres no le han brindado afecto, por lo que siempre ha tenido que ser independiente. Comienza a trabajar a los 16 años para poder pagarse sus estudios. Vive con su prima hasta que da a luz a su hija.

Conoce al padre de su hija en el trabajo, se enamora a inicia sexualmente con el. Mantienen una relación de enamorados hasta que el se va de Lima con otra mujer. Carmen queda embarazada y no se lo menciona al padre hasta el quinto mes. 
Actualmente mantiene sola a su hija y trabaja en costura, se muda con la madre para ahorrar en gastos. Sin embargo, tiene planes de mudarse sola con su hija en el futuro.

\subsubsection{Ser Hombre}

\section{Ser proveedor: El que abandona}

“Yo crecí sin papá, sin mamá, no tuve cariño de mi papá, de mi mamá y eso me duele, Por eso creo que me aferré a él, como no tuve el cariño de padre ni de madre. Como al principio era bien detallista, me apoyaba, me aconsejaba, por eso no mas habré estado con el" (Carmen, entrevista)

Carmen relata que siempre tuvo la figura ausente de ambos y que reconocía la "carencia" de padre "proveedor y protector". Este hecho era de suma importancia para ella, ya que siente que pudo tener influencia en cuanto a su enamoramiento con el padre de su hija.

Siente una profunda "desilusión" porque para ella su padre abandona todos estos "deberes" que le corresponden. Señala que no le paga educación, alimentos, y tampoco fue un suporte para ella. Lo cuenta en la siguiente viñeta:

“De mi papá, ni que hablar, uy... lo conocí a los quince años, tiene otra mujer, solo me pregunta: cómo estás, cómo te ha ido, cómo está en el estudio. De ahí nada. No le importaba nada, no se preocupaba por mi nunca lo hizo..." (Carmen, entrevista)

La figura paternal siempre estuvo ausente, por eso Carmen busca ese soporte en una posible pareja. Parece ser que lo único que reconoce es la ausencia de las cualidades proveedoras.

Al pasar el tiempo, lo que busca Carmen en una posible pareja, es específicamente lo que no le dio su padre, cuenta que lo que le atrajo del padre de su hija es la manera en que el "la cuida" y "la provee" económicamente. También le exige en sus estudios, convirtiéndose en una figura paternal. Se puede apreciar en la siguiente narrativa:

"Como te digo que era bien atento, me daba todo su apoyo, se preocupaba. Me daba plata para estudiar, cuando me hacía falta, me aconsejaba de que tenía 
que estudiar. Me venía a ver al cuarto, me traía alimentos. Me decía: "cómo estás", si “te sientes bien o triste" (Carmen, entrevista)

Es curioso como finalmente se enamora de alguien que no puede mantener ese apoyo de manera sostenida. Carmen cuenta, que el padre de su hija también le ha fallado como proveedor económico y afectivo. "No me ha dado nada, nunca, decía que va a depositar pero solo una ves ha depositado"

Sin embargo, recalca que lo único que pedía era que no le fallen a su hija, de la misma manera que le fallaron a ella. Carmen pide al padre de su hija, que aunque no este presente en su día a día, sea un proveedor estable de afecto y de esta manera evitar que sienta las carencias que ella tuvo en su infancia. Se apreciar este deseo en la siguiente cita:

"Lo importante es que tú, le des algo a tu bebe. A mí me gustaría que tú la veas. No importa lo poco que la veas, que le des cariño, que la veas". (Carmen, entrevista)

Para Carmen, el apoyo económico es parte de su idea de hombre. Sin embargo, en su relato prima lo afectivo y pareciera que le da un mayor valor a esta cualidad en el hombre. Enfatiza que no le gustaría que le fallen como proveedor de afecto y seguridad, lo cual se evidencia en la siguiente viñeta:

"De la nada me decía... él era de tener plata. Será por eso que me compraba mis cosas...no... porque a mí no me interesa lo que me compra, sino lo que yo sentía por él y el cariño, que me apoyen" (Carmen, entrevista)

Para Carmen, la idea de hombre esta marcada por la ausencia. Desde su discurso, recalca la carencia de afecto y sostenimiento que no tuvo por parte de su padre, el cual conoce a los 15 años. Pareciera que para Carmen, el hombre es una figura ausente. Relaciona la ausencia con la infidelidad, creando una desconfianza en sus relaciones. Si bien, tiene la idea de lo que "debería de ser" el hombre como padre o como pareja, pareciera sentir que esta cualidad de proveedor siempre estará ausente en sus relaciones. 


\section{Infiel: La desconfianza}

Carmen cuenta que desde pequeña veía que su padre le era infiel a su madre. La ausencia del padre estaba marcada por la infidelidad ya que este tenia otra pareja y había "abandonado" su hogar. Lo recuerda de la siguiente manera:

"Mi papa yo lo he conocido recién a los 15 años, el tenia otra mujer, le dejo a mi mama embarazada, y se fue así con otra, como todos" (Carmen, entrevista)

Mas adelante, Carmen recuerda que durante toda su adolescencia su madre le "metía la idea" que los hombres eran infieles y que enamorarse era un error. Aunque no adoptara esta creencia como propia, tener ese discurso en su entorno cercano la influenciaba, esto se hace evidente en la siguiente viñeta:

"Mi mamá piensa así: si algún hombre va a estar contigo, es para que tengan relaciones y ya. Te boten. Por eso mi mamá me dice 'no quiero que te enamores de nadie"” (Carmen, entrevista)

Por otro lado, Carmen relata que tiene un tío muy cercano, y que este le dice que nunca "la van a tomar enserio" por ser madre soltera. Nuevamente este tipo de discursos están presentes el entorno de Carmen:

"Así dicen mis tíos. "no esa chica no, solo la utilizo porque es madre soltera, una vez que tenga relaciones la voy a botar". Yo escucho eso. Me sorprende que hablen los hombres así, a pesar de que sean mis tíos. Me dice que no quiero que te enamores, ahora que eres madre soltera, te van a tratar mal. Así me hablan, eso me hace pensar" (Carmen, entrevista)

Pareciera que estos referentes, si bien no los quiere reconocer como propios de alguna manera terminan condicionándola a pensar que el hombre es infiel, y por eso repetir patrones propios de estas ideas.

"Porque yo pienso que los hombres no te toman en serio, solo quieren pasar un rato contigo... no me gustaría pensar así, pero por momentos eso se viene no mas a mi cabeza por todo lo que pasa" (Carmen, entrevista)

Cuando se enamora del padre de su hija, este también le es infiel. Carmen señala que para ella significo una "desilusión" porque pensaba que todo podía ser distinto a lo le trasmitía su entorno, pero termino siendo "igual que todos". 
Finalmente, pareciera que termina des identificándose de este mensaje que tiene también una importante carga familiar de la cual parece que se quiere desentender. Se puede hacer evidente en la siguiente viñeta:

“A pesar de todo, yo pienso que se equivocan. Quizás... a veces tengo la certeza que hay personas buenas en este mundo. Claro, la mayoría son malas, no sé pero hay un 2\% que son buenos. Tengo la esperanza de algún día conseguir una buena persona. No, yo no pienso igual que mi mamá o mis tíos, pero si tengo miedo a equivocarme, sí." (Carmen, entrevista)

\section{Pseudo presente: Fantasía predominante}

Desde su infancia, Carmen cuenta que ha tenido una infancia marcada por una presencia intermitente de su figura paterna. Sabia que tenia un padre que no conocía pero tenia siempre en sus pensamientos. Cuando lo conoce recién a los quince años, mantienen un contacto inestable, pero este esta siempre en su imaginario. Carmen lo cuenta de la siguiente manera:

"A mi papa recién lo he conocido a los 15 años, mi mama asi de veces que me hablaba de el, sabia que tenia mi papa, siempre pensaba pero no estaba pues ahi, ni me apoyaba como un padre no?" (Carmen, entrevista)

Cuando conoce al padre de su hija, este también adopta una postura pseudo presente. Se separa de ella cuando esta gestando y la relación que mantienen es inestable e intermitente. Esto se hace evidente en la siguiente narrativa:

"Luego de ahí se fue, se volvió a ir. No le quise decir hasta los cinco meses. Al principio también me apoyó. Luego de un mes se fue, otra vez. Pero siempre pensaba yo en el, que hará asi"” (Carmen, entrevista)

Esta dinámica se mantiene hasta el nacimiento de su hija, en donde Carmen refiere que siempre "esta pensando en el" y en las promesas que el le hacia con respecto a la mantención de su hija.

"Como yo lo llamo a decirle cuándo va a depositar ... creo que le incomoda y lo cambia de chip. Siempre cambia de chip. Y a veces... ya ni para ubicarlo." (Carmen, entrevista) 
Resulta interesante que actualmente su hija también mantenga a su padre en un ausente y Carmen refuerce la idea que este puede volver, tratando que su padre este presente en la vida de su hija, aunque no tenga participación en su vida cotidiana.

“A veces me pregunta por su papá y no sé qué decirle. A veces le digo que está lejos, que está trabajando, y eso me hace sentir mal.... Pero quiero que siempre sepa que tiene un papa." (Carmen, entrevista)

Coincidentemente, Carmen cuenta que actualmente ha conocido a una posible nueva pareja, con el cual también tendría una relación presente-ausente debido al trabajo de este. Reconoce esta intermitencia como un inconveniente pero sin embargo sigue presentándose esta característica en los hombres de su vida.

"Me impidió, más porque él se iba de viaje mucho tiempo. Se iba y no nos veíamos ya. Nos veíamos a escondidas. Y ya, estábamos bien... hasta que como él tiene presentaciones, se fue a... a dónde se fue... a Huaraz. Ahí no volvió un mes. Apagó su celular, y eso me molestó, porque seguía pensando en el pero no estaba." (Carmen, entrevista)

\subsubsection{Ser Mujer}

\section{En el trabajo: independencia económica}

Carmen relata que tuvo la necesidad de buscar trabajo y salir de su casa porque sus padres no le daban apoyo económico. Esto la "forzó" a que desde pequeña tenga que trabajar para poder pagar sus estudios y buscarse la vida.

"Claro y así pues trabajo, ya no necesito de nadie y eso esta bien porque así yo misma soy por lo que soy, y se a mi niña así no le va a pasar nada, entonces me siento tranquila" (Carmen, entrevista)

Ahora comenta que sigue manteniéndose firme en el trabajo ya que "de ella depende su hija". Pareciera que el ir a buscar trabajo, la ha empoderado a si misma sintiéndose capaz de alcanzar cualquier objetivo que se plantee sobretodo con respecto a la crianza de su hija y lo que es capaz de darle.

“No me importa si tiene papá o no tiene papá, voy a criarla yo sola. Y así, le tomaba más atención a ella, me olvidaba de los problemas que ya tenía, me 
olvidaba. Le daba todo, yo se que todo le puedo dar, cualquier cosa que yo quiera" (Carmen, entrevista)

Carmen señala que el hecho de proveerse económicamente sin ayuda de nadie la hace sentir independiente, y aunque muchas veces puede agobiarse por la presión de tener ue salir a trabajar, es también gratificante para ella.

"Yo decidí comenzar a trabajar por lo que mis papas no me daban, veía a otras compañeras que se compraban una hamburguesa, un cafecito, un menú, y yo no podía. Entonces me dije 'voy a trabajar, voy a trabajar' y me puse a trabajar." (Carmen, entrevista)

Sin embargo, refiere que muchas veces se siente "culpable" por no permanecer en su casa cuidando de su hija y pasando tiempo con ella, pero "no le queda de otra" porque es el único pilar que sostiene a su familia.

"Ay veces me siento mal con mi hija, por lo que trato de darle más tiempo. A veces en el trabajo, como soy un poco renegona, a veces viene y me distrae, y estoy trabajando. De ahi todo bien. Nunca le maltrato a mi hija, pero si mas adelante quiero estar con ella en casa." (Carmen, entrevista)

\section{En la casa: Donde uno no pertenece}

Carmen refiere que desde niña ella no se ha sentido perteneciente a ningún hogar. Su madre se va vivir sola, y ella se queda viviendo con su prima. Según comenta, no existía ningún lugar en el cual ella se sintiera "cómoda".

Desde la experiencia narrada por Carmen, en sus recuerdos desde niña ella siente que no ha vivido en un hogar construido. Ha ido viviendo en diferentes casas, no ha tenido un espacio propio para ella, ha ido de casa en casa acomodándose a otros hogares, sin embargo en este trascurrir ella mantiene la ilusión de en algún momento de su vida construir su hogar.

"A veces, pienso tener un terreno por ahí. Ya a veces como que estoy cansada de vivir a la casa de mi mamá. Todo el día es como que el otro, que no apagas su luz, que estás gastando el agua. Y no me dejaba mucho salir, que por qué estas saliendo, y yo no quería eso para mí." (Carmen, entrevista) 
Hay una expectativa infantil en Carmen que no la deja como adulta construir un hogar desligado de este deseo infantil. Pareciera que busca a una pareja que tape esos vacíos de hogar que viene añorando desde su infancia. Se mantiene en una expectativa idealizada.

Actualmente existe una vivencia de competencia con la madre. Se muda con su madre nuevamente por cuestiones económicas, y siente que debe algo por permanecer en el hogar. No se siente dueña del espacio, pero quiere serlo. Pareciera que Carmen quiere lograr una independencia que implique ser ella la dueña del hogar y poner sus propias reglas en las que se crie su hija.

\subsubsection{Vínculo con la pareja: Mujer cuidadora}

Carmen comenta, que ella solía "proteger" mucho al padre de su hija, aun cuando ella consideraba que el le había hecho daño. Cuando se entera de la infidelidad, Carmen decide no confrontarlo porque para ella confrontarlo significaba dañarlo y hacerlo "sufrir". No quería verlo sufrir como lo señala en la siguiente cita: "Bueno lo tomé tranquila. Lo tomé tranquila, porque no lo quería verlo a él sufrir."

Al encontrarse en un escenario en el que su pareja le es infiel, asumió un rol "materno" que ella lo compara con los sentimientos que una madre siente hacia sus hijos cuando han cometido una falta, infantilizándolo. Ella misma refiere que lo ubica "como a un hijo". Carmen reconoce que se ubica en un segundo plano como mujer y asume el rol protector. Ella se asume como responsable de los hechos, en lugar de confrontarlo como sí ella hubiese cometido la infidelidad. Al respecto ella relata lo siguiente:

“Como a un hijo, yo pensaba primero en él, y en mí no. a veces me daba cosa. Ahorita me pongo a pensar, y digo por qué no le dije en ese rato. Y ¿quién pensaba en mí? Si yo pensaba en él y él no en mí." (Carmen, entrevista)

Esta situación cambia cuando da a luz a su hija. El hombre pasa a un segundo plano, lo deja de lado y su prioridad es ahora su hija. Como lo señala en la siguiente viñeta:

"No me interesaba su papá. Cuando nació mi hija me olvidé, prácticamente. No me interesa. O sea ya no me interesaba, si está con otra o si va a venir o no. Siempre decía que me gustaría, pero si una persona se va, qué voy a hacer. 
Dejaba de llorar, porque antes lloraba. Dejé de llorar porque me dedicaba más a ella." (Carmen, entrevista)

Recalca que ya no le interesa lo que el pueda sentir, debido a la desilusión que siente por su ausencia y falta de responsabilidad. Lo narra de la siguiente manera:

"Yo obviamente ya no regresaría con él. Yo ya no siento nada por él. Hoy en día ya no siento nada por él, más que una decepción grande, porque ni ha cuidado a su hija... ese no sirve” (Carmen, entrevista) 


\section{CAPITULO 4. DISCUSION}

Las cuatro narraciones de estas mujeres dan cuenta de cómo se van construyendo las representaciones de masculinidad a lo largo de la experiencia de vida y las diversas posiciones que van ocupando socialmente. Estas mujeres logran empoderarse posicionándose como mujeres en un lugar importante: dentro de su hogar, en los nuevos roles que cumple como mujer y madre y las posibilidades que va encontrando en el espacio laboral al salir al espacio público (Burin, 2005).

Si bien el eje de la presente investigación no se centra en estudio de aspectos culturales, se encuentra que existe un quiebre entre las representaciones nucleares de la sociedad trasmitidas de manera transgeneracional (Moscovici, 1986) asociadas al marianismo y machismo, desfase que crea un desencuentro entre la realidad y la fantasía que la mujer tiene acerca de los espacios que cree le corresponden. (Fuller, 1995). En todos los casos, esta situación las lleva a replantear su propia identidad y a transformar sus representaciones acerca de la masculinidad (Montesinos, 2004).

La construcción de lo que ellas entienden por Ser hombre se va dando en la interacción con el ambiente. (Carosio, 2014) En todos los casos la construcción es constante, en distintos momentos de sus vidas ven al hombre de una manera en particular. En el caso de Diana, el concepto que tiene de ser hombre equivale al medio que tiene para sentirse cuidada y sostenida económicamente, expectativas que la llevaron a aceptar a una pareja que no necesariamente quería. Por otro lado, para Luz la representación de hombre implicaba cumplir un rol casi maternal y hacerse cargo de sus necesidades afectivas, lo cual la llevó a involucrarse sentimentalmente con su pareja predominando su deseo de tener una familia y ser contenida afectivamente. En ambos casos estas mujeres habían crecido escuchando un discurso familiar que sostenía una postura de mujer indefensa, lo que coincide con lo que Fuller (2005) denomina la mujer a la imagen de la virgen María.

Mujeres como Diana, Luz y Berta esperaban en un primer momento encontrar en la elección de su pareja a alguien semejante a su figura paterna a quien la tenían idealizada. 
En esta misma línea, el caso de Carmen, ante la ausencia de su padre biológico recién conoce al padre a sus quince años-, primaba la búsqueda de una figura paternal, que la sostuviera de manera económica principalmente, a la misma vez alguien que establezca reglas y vea por ella. Aspectos que se encontraban en una representación idealizada, dado que ella no había tenido una relación con un padre real. La representación de lo masculino se ha construido en un discurso que viene desde la infancia con el modelo de padre sobreprotector (Caamaño, 2010). Sea por identificación con el padre presente idealizado o por la idealización de un padre ausente. Una pregunta interesante a realizarse es si son mecanismos de estas mujeres para no sentirse abandonas por el padre y tener que vivir el duelo.

Luego de establecer un vínculo de pareja, guiadas por estas representaciones, en los cuatro casos ocurre una infidelidad por parte del padre de sus hijos. En un primer momento, cuando se descubre la infidelidad surge un cuestionamiento de lo que están viviendo, junto con un derrumbe de la imagen idealizada que ellas tenían de la familia y de la pareja, lo que las hace entrar en un proceso de duelo que no todas han llegado a elaborar. (Freud, 1915) Luz menciona sentirse perdida y que con el pasar del tiempo se fue rehaciendo como mujer. Para Diana la idealización era tan fuerte que se deprimió, se encerró descuidando a sus hijos y su propia salud. Frente a la infidelidad de su pareja, le resultó difícil aceptar los hechos que estaba viviendo, asumiendo que su tarea en adelante consistía en intentar ayudarlo a que cambie. Posicionándose desde un rol materno, manejo que evitó a que exprese su agresividad (Caamaño, 2010).

Un hallazgo de este estudio revela el desencuentro entre el hombre idealizado y el hombre real portador de infidelidad (Montesinos, 2005). Esto las lleva a un proceso de duelo cuyo manejo implicó salir del espacio privado al espacio público como un recurso importante que las llevó a encontrarse con voces de otras mujeres que activaron en ellas una fuerza motivadora. Les proporcionó un continente importante que las llevó a desmitificar al hombre. Para estas mujeres, aun de confrontarse con lo doloroso de la infidelidad de sus parejas, al mismo tiempo este suceso se convirtió en un motor de cambio para la propia identidad. En adelante, la nueva representación respecto a la masculinidad es hacer un equivalente del hombre y la infidelidad. Parece ser que aún en adelante, estas mujeres no saben como relacionarse con un hombre que no sea infiel, ya que en su psique la representación de hombre se encuentra estrechamente ligada a connotaciones negativas como infidelidad, violencia y abandono "pa que ya uno se mete un hombre, ya ni quiero tener hombre siempre triste te deja no mas... ya mejor sola" 
(Luz, entrevista). No existe una elaboración personal de la situación que pueda ayudarlas a ver distintas maneras de relacionarse.

Posteriormente cambia la posición que el hombre tiene en la vida de estas mujeres. De ser un elemento indispensable pasa a ser una persona intermitente en sus vidas. En el caso de Luz, Diana y Berta el hombre deja de ser pareja para convertirse únicamente en padre de sus hijos. Buscan que se acerquen al espacio privado como padre de sus hijos pero inconscientemente una parte de ellas los espera como mujer para satisfacer su necesidad de ser miradas, queridas y reconocidas como mujeres. Paradójicamente ellas no han perdido la esperanza de volver a ser deseadas como mujeres atractivas, ocasionalmente concretan encuentros íntimos.

En tres de los casos, la posibilidad de encontrar una nueva pareja se ve ofuscada por un sentimiento de temor que se repita el abandono y la infidelidad con la desesperanza al referir que todos los hombres son iguales (Gogna, 1998). Por ejemplo, Luz manifiesta explícitamente su temor de la siguiente manera "Yo pienso que ya todos los hombres son así. O sea yo tengo miedo de formar otra así de meterme con alguien que digo de repente me va a dejar así nuevamente ilusionada”.

Solo una de las participantes tiene la esperanza de encontrar el amor. Resulta muy curioso que esta mujer sea la única que se encuentre en la década de los veinte años. Siendo la más joven todavía tiene una expectativa idealizada de encontrar una nueva pareja de acuerdo a sus deseos. Se mueve basada en expectativas que tenían las demás participantes a su edad, demostrando como surge primero una representación idealizada del hombre y lo que puede proveer:

“A pesar de todo, yo pienso que se equivocan. Quizás... a veces tengo la certeza que hay personas buenas en este mundo. Claro, la mayoría son malas, no sé pero hay un 2\% que son buenos. Tengo la esperanza de algún día conseguir una buena persona. No, yo no pienso igual que mi mamá o mis tíos, pero si tengo miedo a equivocarme, sí."

Para las participantes de este estudio ser mujer es una combinación entre la propia autopercepción y las ideas nucleares trasmitidas en la familia. Han crecido escuchando un discurso de la madre que recalca la importancia que tiene la mujer en el espacio privado, enfatizando la subordinación de la mujer en el espacio público al identificarla con la idea de ser el soporte afectivo y doméstico (Schmukler, 1989 como se cita en Marcús, 2006). La maternidad también se entiende como una fuente de poder 
a partir del espacio privado, puesto que además de otorgarle un sentido a sus vidas, les permite tener control sobre sus hijos (Fuller, 1995). Sus nuevos amores, que en su fantasía se van a quedar a su lado y no las van a abandonar.

Para estas cuatro mujeres la maternidad se encuentra ligada a la identidad femenina, siendo una gran parte de lo que significa para ellas ser mujer. En su discurso, se puede notar como el ser madre les otorga plenitud en cuanto a su identidad, ya que sus hijos son fuente de alegría y satisfacción (Marcus, 2006). En el caso de Diana, Berta y Luz pensaban en el hombre como el que les daría esta satisfacción de ser madres, lo que resultaba en que busquen de manera no consciente a un padre para sus hijos, mas no una pareja.

Sin embargo, cuando ocurre la separación del padre de sus hijos se identifican de manera consciente en la realidad actual del país y Latinoamérica que impulsa la igualdad de oportunidades entre el hombre y la mujer (Carosio, 2014). Las creencias periféricas de la sociedad influyen en ellas consolidando una fortaleza interna. Se enfrentan a ellas mismas, se vuelven padre y madre rompen el limite del espacio privado y comienzan a ejercer autoridad también en el ámbito publico como corrobora Montesinos (2004) en su investigación en un país latinoamericano. Este posicionamiento nos permite ver como se han ido transformando las representaciones de masculinidad para ellas a lo largo de su experiencia hasta el momento de a presente investigación. Al ver que pueden cumplir un rol que había sido entendido únicamente como masculino, en algunos casos lo infantilizan y se desligan en gran parte de ellos.

Es en este momento donde surge el tema del empoderamiento ellas parten de una necesidad, tienen que darle de comer a sus hijos porque están solas, y no cuentan con el hombre proveedor que ellas esperaban. Empiezan a trabajar por una necesidad real, pero luego eso trasciende y les da una representación de ellas mismas en otros escenarios y dejan de convertirse en las madres que solamente estaban para solamente prepara la comida de sus hijos. Ellas descubren que también pueden ser proveedoras.

Otro hallazgo importante de esta investigación se centra en el desencuentro entre el discurso de estas mujeres en las entrevistas y el mensaje que le trasmiten a sus hijos. Por ejemplo, Luz nos da un mensaje de fortaleza femenina y de cambio en la manera de ver a los hombres a partir de sus experiencias, pero cuando habla con su hija el discurso da un giro, asemejándose al mensaje que le trasmitían sus padres cuando era niña.

Se podría sostener que estas representaciones en cuanto a ser mujer se encuentran instauradas en la propia subjetividad (Chodorow, 1999), haciendo mas 
difícil que se procesen los cambios en las creencias nucleares. Sigue existiendo un conflicto interno en estas mujeres, no pueden entender porque el hombre las abandona ¿yo que le he hecho, porque a mi? es una pregunta frecuente que se hacen las entrevistadas. Es posible que en los cuatro casos, ellas no se han dado el espacio para procesar internamente aspectos mas subjetivos como la herida narcisista que sienten que les deja este hombre al abandonarlas. Este no procesamiento podría llevarlas a que re trasmitan ese mensaje transgeneracionalmente a sus hijos, repitiéndose el mismo patrón vincular.

Existe una fortaleza que se encuentra en un nivel consciente y periférico, sin embargo hay una herida que no se ha podido curar del todo. Este fenómeno también se hace presente en las representaciones de masculinidad de la mujer. Pasan de una idealización del hombre a denigrarlo y verlo como algo que pude dañar a sus hijas. Esta representación se extiende hasta los hijos hombres, donde se les atribuye desde ya el ser infieles en el futuro con sus propias mujeres, como una suerte de destino del cual es casi imposible escapar.

En cuanto a las conclusiones, el presente estudio fue un reto al buscar incorporarse, comprender y el acercase a un espacio íntimo y profundo del relato de las mujeres-madres solteras, quienes se han visto en la necesidad de cumplir un doble rol en la vida de sus hijos: padre y madre. El objetivo fue describir como se construyen las representaciones de masculinidad de estas mujeres a lo largo de su experiencia de vida. Al recoger la información, esta se analizó en tres ejes temáticos que emergieron del contenido de las entrevistas. Así mismo, la mirada empática de la investigadora y los sentimientos que surgieron fueron claves para tratar de comprender y acompañar a estas mujeres en un discurso cargado de afectos, muchas veces difíciles de recordar.

Finalmente una de las limitaciones se encuentra que si bien la información recogida ha abarcado muchos temas de importancia, el tema de la violencia física y psicológica no se indagó a profundidad. Una de las interrogantes que surge es como estas mujeres no establecen la conexión entre los compartimientos de infidelidad y la vivencia de la violencia. Esta no elaboración abre una posible nueva línea de investigación. Una hipótesis a construir es que en nuestra sociedad la infidelidad ha pasado a normalizarse y no se vive como un acto de violencia. Siendo una limitante al no explicitarse la pregunta para que ellas pudieran conectar en sus narrativas. 


\section{REFERENCIAS BIBLIOGRAFICAS}

Benjamin, J. (1997). Sujetos iguales, objetos de amor. Buenos Aires: Paidós.

Bowly, J. (1980). The origins of attachment theory. New York: Willey Blackwell.

Burin, M. (2004). Genero femenino, familia y carrera laboral: Conflictos vigentes. Subjetividad y procesos cognitivos, 48-77. Recuperado de http://xenero.webs.uvigo.es/profesorado/mabel_burin/articulo_mabel_burin.pdf

Burin, M. (2007). El techo de cristal en la carrera laboral de las mujeres. Acerca del deseo de poder en las mujeres. En M. Alizade, \& B. Seeling (Eds.), El techo de cristal (pp. 48-77). Buenos Aires: Editorial Lumen.

Buss, D. \& Barnes, M. (1986). Preference in Human mate selection. Journal of personality and social Psychology, 50, 559-570.

Caamaño, E. (2010). Mujer y trabajo: origen y ocaso del modelo del padre proveedor y la madre cuidadora. Revista de derecho,34, 179-209.

Callirgos, J. (1996). ¿El otoño del patriarca?. Lima: Dirección General de Educación Superior para Profesionales de la Educación.

Carosio, A. (2009). Feminismo latinoamericano: imperativo ético para la emancipación. Buenos Aires: Consejo Latinoamericano de Ciencias Sociales.

Cavero, R. (2008). La relación de pareja. Apego dinámicas de interacción y actitudes amorosas: consecuencias sobre la calidad de la relación. Valencia: Servei.

Connel, R. (1997). La organización social de la masculinidad. Recuperado de: http://www.pasa.cl/wpcontent/uploads/2011/08/La_Organizacion_Social_de_la_ Masculinidad_Connel_Robert.pdf

Cornejo, M., Mendoza, F., \& Rojas, R. (2008). La investigación con relatos de vida: pistas y opciones del diseño metodológico. Psykhe, 17(1), 29-39.

Chodorow, N. (1999). El poder de los sentimientos. Buenos Aires: Paidos.

Escribens, P. (2011). Proyecto de vida en mujeres victimas de violencia sexual en conflicto armado interno (Tesis de licenciatura, Pontificia Universidad Católica del Perú). $\quad$ Recuperado de http://tesis.pucp.edu.pe/repositorio/handle/123456789/828

Flores-Galindo, C (2014). Hegemonía masculina y violencia en relaciones de pareja de mujeres de SJL (Tesis de licenciatura, Pontificia Universidad Católica del Perú). Recuperado

de 
http://tesis.pucp.edu.pe/repositorio/handle/123456789/25/browse?value=Flores + Galindo+Rivera\%2C+Carlos $+\mathrm{Ra} \% \mathrm{C} 3 \%$ BAl\&type $=$ author

Freud, S. (1932). Sobre la sexualidad Femenina. Buenos Aires: Editorial Amorrotou.

Freud, S. (1984). Duelo y Melancolía. Buenos Aires: Editorial Amorrortou.

Fuller, N. (1996). En torno a la polaridad machismo-marianismo. Anuario de hojas de Warmi, 7, 11-18.

Fuller, N. (1992). Dilemas de la femineidad: mujeres de clase media en el Perú. Lima: Fondo Editorial Pontificia Universidad Católica del Perú.

Fuller, N. (1997). Fronteras y retos: Varones de clase media en el Perú. Lima: Fondo Editorial de la Pontificia Universidad Católica del Perú.

Fuller, N. (1998). Discursos y representaciones de masculinidades entre varones de clase media del Perú. Espacio Abierto, 7(1), 61-78.

Fuller, N. (2012). Repensando el machismo latinoamericano. Masculinities and Social Change, 1(2), 114-133. doi: 10.4471/MCS.2012.08

Gogna, M., Llovet, J., Ramos, S. \& Romero, M. (1998). Los retos de la salud reproductiva: derechos humanos y equidad social. Buenos Aires: Norma.

Gonzales-Rey, F. (2007). Personalidad y Salud: La dimensión Subjetiva en la salud humana. Revista Cubana de Psicología, 12(2-3), 135-143.

Gutmann, M. (2003). Changing Masculinities in Latin America. North Carolina: Duke Press.

Instituto Nacional de estadística e informática (2014). Perú: Encuesta demográfica y de salud familiar. Lima, Perú: INEI.

Jodelet, D. (2008). El movimiento de retorno al sujeto y el enfoque de las representaciones sociales. Cultura y representaciones sociales, 3(5), 32-61.

Kimmel, M., Hearn, J. Connell, R. (2004). Handbook of studies on men \& masculinities. New Dehli: Sage publications.

Lamas, M. (1996). Cuerpo: Diferencia Sexual y Genero. Lima: Taurus.

Manuela Ramos. (2011). Una respuesta comunitaria frente a la violencia contra las mujeres. Lima: Manuela Ramos.

Marcús, J. (2006). Ser madre en los sectores populares: una aproximación al sentido que las. Revista argentina de sociología, 4(7), 100-119.

McKlnney, B. \& Peterson, R. (1987). Predictors of stress in parents of developmentally disabled children. Journal of Pediatric Psychology, 12(1), 133-150. 
Burin, M. (2007). El techo de cristal en la carrera laboral de las mujeres. Acerca del deseo de poder en las mujeres. In M. Alizade, \& B. Seeling, El techo de cristal. Buenos aires: Editorial Lumen.

Fuller, N. (1997). Fronteras y retos: Varones de clase media en el Peru. In J. Olavarria, \& T. Valdes, Masculinida/es: Poder y crisis. Santiago: Flasco.

Ministerio de la mujer y poblaciones vulnerables. (2014). El costo de la desigualdad de genero en el Peru. Hacia la igualdad de derechos entre hombres y mujeres .

Person, E. (2007). Sexo, jerarquia y poder. In M. Alizade, \& B. Seelig, El techo de cristal. Buenos aires: Editorial Lumen.

Montesinos, R. (2002). La masculinidad ante una nueva era. El Cotidiano, 16(113), 3746.

Montesinos, R. (2004). La nueva paternidad: expresión de la transformación masculina. Polis: Investigación y Análisis sociopolítico y psicosocial, 2(4), 197-220.

Montesinos, R. (2004). Los cambios de la masculinidad como expresión de la transición social. El cotidiano, 20(126), 1-16.

Montesinos, R. (2005). La masculinidad en ciernes: resistencias y conflictos en la construcción social de una presencia urgente. Masculinidades emergentes, Universidad Autónoma Metropolitana-Iztapalapa y Miguel Ángel Porrúa, 1, 1347.

Mora, M. (2002). La teoría de las representaciones sociales de Serge Moscovici. Athenea digital: revista de pensamiento e investigación social, 2, 78-102.

Olavarría, J. (2003). Los estudios sobre masculinidades en América Latina. Anuario Social y político de américa latina y el caribe. Anuario Social y Político de América Latina y El Caribe, 6, 91-98.

Person, E. (2007). Sexo, jerarquia y poder. En M. Alizade, \& B. Seelig, El techo de cristal (pp. 55-86). Buenos Aires: Editorial Lumen.

Ráez de Ramírez, M. (1998). Personality development of women leaders: assessment studies in Peruvian urban and poverty areas. Nijimegen: Katholieke Universiteit Nijmegen.

Raguz, M. (1995). Construcciones sociales y psicologicas de mujer, hombre, femineidad, masculinidad y género en diversos grupos poblacionales. Lima: PUCP. 
Raguz, M. (2013). Violencia y discriminación de género, contra la mujer y la diversidad sexual. Inédito.

Ramos Padilla, M. (2007). Masculinidad y violencia familiar. Lima: Movimiento Manuela Ramos.

Sánchez, A. \& Margarita, I. (2010). La construcción de las masculinidades entre adolescentes trabajadores de Lima, Perú. Revista internacional de Ciencias Sociales y Humanidades, 1, 161-177.

Sandler, J. \& Sandler, A. (1978). On the development of object relationships and effects. International Psychoanalisis Journal, 59, 258-295.

Stake, R. (1995). The case study method in social inquiry. Educational Researcher, 7(2), $5-8$.

Stoller, R. (1968). Sex and Gender: On the devolpment of masculinity and feminity. New York: Science House.

Tyson, P. \& Tyson, R. (2000). Teorías Psicoanalíticas del Desarrollo. Lima: Publicaciones Psicoanalíticas.

Valenzuela, J. (2011). Funciones de las Instituciones públicas y comunitarias frente a la violencia familiar y sexual. Lima: Movimiento Manuela Ramos.

Valenzuela, J. (2012). Servicios de atención de la violencia familiar y sexual de la provincia de Cotabambas. Lima: Movimiento Manuela Ramos.

Viveros Vigoya, M., Olavarría, J., \& Fuller, N. (2001). Hombres e identidades de género. Investigaciones desde América Latina. Colombia: Universidad Nacional de Colombia. 


\section{ANEXOS}

\section{Anexo 1. Ficha demográfica}

1. NOMBRE:

2. EDAD:

3. ESTADO CIVIL:

4. LUGAR DE NACIMIENTO:

5. GRADO DE INSTRUCCIÓN:

PRIMARIA: COMPLETA / INCOMPLETA

SECUNDARIA: COMPLETA / INCOMPLETA

TECNICA/ SUPERIOR: COMPLETA / INCOMPLETA

6. ¿POR QUIEN FUISTE CRIADA? (papá, mamá, abuelos, tíos, otros):

7. N. DE HIJOS:

8. EDADES DE LOS HIJOS:

9. SITUACION LABORAL/ OCUPACION: 


\section{Anexo 2. Guía de primera entrevista}

"Buenos días como ya habíamos conversado, estoy realizando una investigación sobre elección de pareja y masculinidad, y como me comentó su interés por contarme un poco acerca de su historia. Esta entrevista va ser grabada, por lo tanto le pediré que firme el siguiente consentimiento si está de acuerdo. Nuevamente muchas gracias por su colaboración, lista para empezar?"

Pregunta Generadora

- “Háblame de tus amores...":**

* Buscó evocar las relaciones mas significativas con las figuras masculinas importantes en su vida.

Temas de abordaje:

- Pareja actual

- Ella como mujer

- Hijos

- Padre de los hijos

- Enamoramientos (distintas etapas)

- Dificultades cotidianas

- Hombre ideal vs hombre real 


\section{Anexo 3. Guía de segunda entrevista}

Frase generadora: "Háblame de los amores de tu infancia."

- * Construcción de la historia familiar haciendo un recorrido de sus vínculos y relaciones con figuras representativas de su ámbito familiar.

Temas de abordaje

- Amores de la infancia

- cuéntame de cuando eras niña

- como era la relación con papa

- como era la relación la mama

- como era la relación de la pareja cuidadora

- como te relacionabas con tus hermanos (recorrido por etapas)

- Como son los hombres en tu familia, en que se parecen en que se diferencian.

- Recorrido en la adolescencia de cuanto tiempo duraron, que las lleva a empezar y a terminar (quien termina) y cuantas parejas tuvo en su adolescencia

- Como te relacionas con los hijos. Como se imagina a los hijos (as) como mujer a futuro.

- Como te ves como mujer, como te has transformado

Pregunta Final “Alguna vez por esas cosas, se te paso por la cabeza ser hombre??" 


\section{Anexo 4. Consentimiento informado.}

Yo, , de años de edad, acepto de manera voluntaria participar en una investigación sobre representaciones de masculinidad y elección de pareja que consta de la participación en tres reuniones donde se me entrevistará, por aproximadamente una hora y se me pedirán ciertos datos que serán consignados en una ficha. La entrevista será grabada y realizada por Alejandra Abusada, Estudiante de Psicología de la Universidad Peruana de Ciencias Aplicadas. La aplicación de ambos instrumentos se realizará como parte de una investigación para optar el grado de Licenciatura con Mención en Psicología Clínica:

- La investigadora se compromete a no revelar la identidad de la participante en ningún momento de la investigación, ni después de ella.

- Los resultados de las entrevistas grabadas servirán para los fines académicos de la investigación, salvaguardando siempre la identidad de la participante con un código.

- La investigadora se compromete a brindar los resultados de la investigación a la participante si así ella lo desea.

- Para cualquier información adicional o dificultad podrán contactarse con la investigadora al correo electrónico u201012929@upc.edu.pe o al número 984205905.

Lima, de del 2015.

Nombre y firma de la participante

Nombre y firma de la investigadora

He sido informado (a) de las condiciones bajo las cuales acepto participar en la investigación. Lima de del 2015

Nombre y firma de la investigadora

Nombre y firma de la participante 